\title{
D PIEDRA NEGRA, TINTA AGUADA Y ALBAYALDE. LAS TÉCNICAS DE DIBUJO DE JOAN DE JOANES Y EL 'ESTADO DEL ARTE' EN LA VALENCIA DEL SIGLO XVI. ¿TRADICIÓN O INNOVACIÓN?'
}

MIQUEL A. HERRERO-CORTELL

Centre d'Art d'Època Moderna-CAEM. Universitat de Lleida miquelangel.herrero@hahs.udl.cat

ISIDRO PUIG SANCHIS

Departamento de Comunicación Audiovisual, Documentación e Historia del Arte. Universitat Politècnica de València ispuisan@upvnet.upv.es

Resumen: El presente artículo pretende realizar un somero análisis al corpus de dibujos sobre papel atribuido a Joan de Joanes y a sus más directos seguidores, desde una óptica metaformal, adentrándose en la génesis misma de tales diseños, desde su concepción hasta sus funciones. Han sido muy eventuales las apreciaciones sobre los procedimientos gráficos usados por el pintor y, en general, la cuestión de sus dibujos se ha abordado siempre desde la tradicional perspectiva de confrontación iconográfica y formal. No se ha ahondado en cuestiones que, a nuestro parecer, resultan claves para entender una figura tan poliédrica y compleja como la del artista valentino: como cuánto débito existe entre el ductus gráfico de Joanes y el de su padre, y qué relación guarda con la tradición hispana; o hasta qué punto puede ser la visualización de modelos y estampas italianas la responsable de su marcado italianismo. Se propone una revisión que incide en la técnica y en la elección procedimental como una vía de ida y vuelta para explicar los vínculos entre su dibujo y su metodología pictórica (más allá de la superficial apariencia). Se trata de aspectos que, en última instancia, hunden sus raíces en la praxis pictórica y en los rudimentos del oficio; en los mecanismos de trabajo del obrador y su funcionamiento; aspectos como la fijación de modelos o el uso de procedimientos mecánicos de seriación.

Palabras clave: dibujos / Joan de Joanes / procedimientos gráficos / papel / Renacimiento.

WITH BLACK PENCIL, INK WASHES AND WHITE LEAD HIGHLIGHTS. DRAWING TECHNIQUES BY JOAN DE JOANES AND THE STATE OF THE ART OF DESIGN IN VALENCIA IN THE 16TH CENTURY. TRADITION OR INNOVATION?

Abstract: The present paper intends to make a brief analysis of the corpus of drawings on paper attributed to Joan de Joanes and his most direct followers, from a metaformal approach, going into the very genesis of such designs, from their conception to their functions. There are very few references about the graphic procedures used by the painter and, in general, the question of his drawings has always been approached from the traditional perspective of iconographic and formal confrontation. There is an evident lack of deepening in questions that, in our opinion, are key to understanding a such complex figure. How much debit is there between the graphic ductus of Joanes and that of his father? And what relationship does it have with the Hispanic tradition? To what extent can it be the display of Italian models and prints responsible for its marked Italianism? A revision devoted to technique and the procedures is done to explain the links between his drawing and his pictorial methodology (beyond the superficial appearance). These are aspects that, ultimately, have their roots in the pictorial praxis and in the rudiments of the job. They constitute the working mechanisms of the workshop. The article finally intends to deal with aspects such as the fixation of models or the use of mechanical procedures of transferring.

Key words: drawings / Joan de Joanes / graphic procedures / paper / Renaissance.

* Fecha de recepción: 15 abril de 2019 / Fecha de aceptación: 22 de julio de 2019.

1 A la memoria de Lorenzo Hernández Guardiola. 


\section{Introducción. Evidencias gráficas en la Valencia Joan de Joanes: convergencias y divergencias ${ }^{2}$}

En confrontación con la abundancia de obras pictóricas y datos exhumados alusivos a los pintores que operaban en la Valencia renacentista, el panorama gráfico de la ciudad a inicios de la decimosexta centuria se revela paradójicamente ignoto. Son tan pocos los ejemplares de diseños de los que se tiene datos, que realizar una aproximación al dibujo valenciano en la época apoyado en evidencias sobre papel resulta una tarea infructuosa. Pero en general, el problema parece tener un alcance espacial mucho mayor: a diferencia de Castilla, los vestigios gráficos de los artistas de los territorios peninsulares de la Corona de Aragón durante el siglo XVI son notablemente exiguos, existiendo una escasa representación de los mismos en las diversas colecciones nacionales e internacionales. ${ }^{3}$ Prácticamente es el dibujo valenciano el único que parece tener una modesta presencia, ${ }^{4}$ siendo el aragonés escasísimo y el catalán inexistente. ${ }^{5} \mathrm{El}$ dato resulta cuanto menos curioso, si se piensa en la Corona aragonesa como una tierra en la que la prodigalidad de la actividad artística y pictórica no es nada desdeñable; un territorio en el que el uso de la 'mostra', además de estar profusamente documentado, se perpetúa en el tiempo. ${ }^{6}$

Conviene recordar, como premisa, que durante los siglos XV y XVI, fue Valencia, de hecho, el primer punto del territorio hispano que adoptó las fórmulas gráficas italianas, gracias al influjo de los artistas que, formados en la península Itálica, operaron en esta ciudad.? Sin duda, el desarrollo de la praxis gráfica tuvo que adquirir en la urbe levantina una notable importancia, como resultado de la copia y reelaboración de modelos, algo que puede colegirse del estudio de la pintura de los maestros valencianos, especialmente a partir de $1500 .{ }^{8}$ Sin embargo, comparativamente con otras áreas territoriales, la que debió de ser una fructífera producción gráfica ha dejado contadísimos ejemplos, algo que debe explicarse por causas como el obvio carácter efímero del soporte o el uso funcional de los dibujos, que justifican en parte dicha tara. ${ }^{9}$ Prácticamente solo se conservan dibujos dispersos del binomio de Yáñez-Llanos (o acaso de su taller), ${ }^{10} \mathrm{y}$ de Joan de Joanes (y obrador) y, pese a alguna salvedad muy excepcional como ejemplares de Nicolás Borrás, el dibujo valenciano carece de mayor representación. ${ }^{11}$

El repertorio fundamental de dibujos joanesco ${ }^{12}$ pese a constituir un corpus relativamente escaso,

2 El presente trabajo se ha beneficiado de la ayuda de Formación del Profesorado Universitario (FPU14/01768) del Ministerio de Educación Cultura y Deporte; al tiempo que se inscribe dentro de las actividades del proyecto de investigación consolidado ACEM (Art i Cultura d'Ėpoca Moderna), de la Universitat de Lleida, y reconocido por la Generalitat de Catalunya (2017 SGR 00712).

${ }^{3}$ De hecho, como ya observan McDONALD, Mark, 2012, p. 45 y FAIETTI, Marzia; GALLORI, C.; MOZZATI, T. (com.), 2018, p. 42; las noticias del dibujo hispano durante la primera mitad del siglo XVI son muy limitadas, y todavía más las de la centuria anterior. También expresa la misma idea NAVARRETE, Benito, 2016, p. 91. Véase igualmente NAVARRETE, Benito, 2018, donde se reafirman gran parte de nuestras afirmaciones.

${ }^{4}$ Esto puede deducirse de diversas publicaciones que versan en torno a colecciones de diseños hispanos, como las de BOUBLI, Lizzie, 2015, pp. 29-131, o más recientemente la de NAVARRETE, Benito, 2016, pp. 381-415.

5 Véase MCDONALD, Mark, 2018, pp. 42-46. Un somero vistazo al catálogo de dibujos del MNAC proporciona una idea de la magnitud de tal observación (Consultado en catálogo en línea el 16/04/2018)

${ }^{6}$ De hecho, se trata de un contexto espacial en el que el dibujo es ampliamente utilizado: además de para conformar repertorios figurativos de modelos de taller, se erige como uno de los mecanismos de trasmisión de conocimiento, al menos desde la Edad Media, al tiempo que adquiere un valor como medium hacia la materialización de la idea. Sobre el uso de las muestras y su dilatada tradición, aunque no llega en su estudio al siglo XVI, resulta imprescindible el trabajo de MONTERO, Encarna, 2015, pp. 77-116, 170-220. Sobre el dibujo como herramienta en el aprendizaje durante el Renacimiento véase HERREROCORTELL, M. Ángel, 2018, pp. 81-106.

7 MC DONALD, Mark, 2012, p. 163. Por este motivo, a lo largo de nuestro trabajo nos centraremos más en comparar los dibujos valencianos con los italianos, cuya similitud es mucho mayor que con sus coetáneos hispanos.

8 Sobre la copia como estrategia en la producción artística del Renacimiento véase: HERRERO-CORTELL, M. Ángel, 2018 a.

9 Para un panorama del dibujo como instrumento funcional en el seno de los obradores resulta fundamental el estudio de BAMBACH, Carmen, 1999.

10 Por más que hayan sido todos atribuidos a Fernando Yáñez, (BENITO, Fernando, 1998, pp. 144-147); (BOUBLI, Lizzie, 2015, pp. 29-44), al tratarse de repeticiones no puede descartarse la mano de otros maestros del círculo copiando a Yáñez. Algunos autores como McDONALD, Mark, 2018, p. 45, dejan la cuestión más abierta, al asumir que a ni a Yáñez ni a Llanos puede atribuírsele con total certeza ninguno de los diseños del binomio.

11 McDONALD, Mark, 2012, p. 167.

12 BENITO, Fernando, 2000 a y b; y BOUBLI, Lizzie, 2015, pp. 81-131. 
es quizás el mejor representado de todos los artistas valencianos (y también de la Corona Aragonesa) del siglo XVI, en consonancia con la larga trayectoria pictórica de su taller. ${ }^{13}$ Entre las tipologías de dibujos que se le conocen destacan los bocetos y estudios composicionales de tablas, los estudios de figuras, (acaso como repertorio de tipos de obrador) y las muestras. En cierto modo, en el grafismo de Joanes conviven en una misma encrucijada italianismo, flamenquismo, e hispanismo, ${ }^{14}$ -como ya se ha advertido, y como sería de esperar en un artista de su talla, en la koiné de la Valencia de su tiempo-, y esto ha generado importantes confusiones, no solo en su pintura sino también en su obra gráfica. ${ }^{15}$

A causa de tales débitos, su estilo gráfico es complejo, quizás algo más de lo que se ha pretendido. Lizzie Boubli planteó una suerte de continuación para las metodologías de dibujo de Joan de Joanes, poniéndolas en relación con el modo de dibujar de Macip, y con la tradición de Paolo de San Leocadio y especialmente de Yáñez de la Almedina. ${ }^{16}$ Es bien cierto que el taller de los Macip fue ejemplar en lo que a la trasmisión de modelos se refiere, puesto que las estrategias de una producción tan abundante pasaban por poder tener recursos con los que responder a diversos encargos al mismo tiempo, como sucedía con otros obradores de prolífica producción, como por ejemplo el obrador de Llanos. ${ }^{17}$ De hecho, puesto que no parece haber una ruptura en el ritmo de encargos ni en las modalidades de trabajo -y efectivamente la seriación de tipos es un hecho constatable en la producción Joanesca-, la afirmación de Boubli ${ }^{18}$ podría parecer a todas luces lógica. Sin embargo, aceptando tal premisa, resulta necesario apuntar algunos matices y puntualizaciones para algunos aspectos, comenzando por no poder obviar que, ante todo, para poder establecer una relación de continuidad con la obra gráfica de su padre, Vicente Macip, sería necesario disponer de alguna evidencia autógrafa que permitiese tal comparación. En general, todos los diseños de Joanes resultan mucho más orgánicos y menos hieráticos que las figuras conocidas de su progenitor, ahora que el respectivo corpus de ambos autores parece ya perfectamente definido, ${ }^{19}$ y aunque es indudable apreciar los débitos de la trasmisión de conocimientos propia de un taller familiar, es cierto que también se evidencian modos de hacer muy diversos.

Pero lo cierto es que nada se conoce sobre los dibujos de Macip, ${ }^{20}$ ni de los de la generación de pintores de transición como los Osona, o Paolo de San Leocadio. Conocemos, no obstante, sus dibujos subyacentes, próximos entre sí y lejanos de los de Joanes. Se trata de dibujos en los que la línea

\footnotetext{
13 Hasta la fecha se tiene constancia de 16 dibujos atribuidos a Joanes (aunque unos pocos quizás deberían considerarse papeles del obrador). No se ha considerado en este recuento un dibujo que claramente presenta una atribución errónea: La Caída camino del Calvario, conservado en The John Paul Getty Museum (inv. 94. GA.95) que por fuerza debe quedar totalmente fuera del corpus gráfico joanesco. El criterio de exclusión este dibujo se basa tanto en el ductus, como en la técnica gráfica usada, pero, sobre todo, en los estilemas. El particular modo de dibujar rostros, manos, y pies, así como la característica forma de drapear de Joanes no parecen encajar con el modo de elaboración de las figuras de dicho ejemplar, ni en su concepción fisonómica ni en su resolución formal. Además, el dibujo no puede relacionarse con ninguna de sus pinturas, ni tampoco con las atribuidas a su padre.

http://www.getty.edu/art/collection/objects/469/juan-de-juanes-juan-macip-christ-carrying-the-cross-spanish-about-1560/

${ }^{14}$ Sobre el tema véase COMPANY, Ximo; PUIG, Isidro; VILALTA, M. José (eds.), 2009. Ciertamente no existe una total paridad en tal convivencia de influjos. Los ecos florentinos y romanos pesan muy por encima de otras influencias, e incluso el cierto poso flamenco de sus figuras parece prevalecer frente a lo puramente hispano, con un cierto regosto a diseños de Jan Gossart, Maarten van Heemskerck, Hendrick Goltzius, y en general los manieristas de la escuela antuerpiense, especialmente.

15 Un buen ejemplo sería su Juicio de Paris, conservado en el Civici Musei e Gallerie di Storia ed Arte de Udine, que estuvo catalogado como pintor flamenco hasta que Pérez Sánchez, en 1979 lo atribuyó a Joanes (BENITO, Fernando, 2000 a, p.124). En la obra gráfica suceden casos análogos: el dibujo del Entierro de San Esteban, conservado en los Uffizi, y perteneciente a la colección Santarelli, fue atribuido durante un cierto tiempo a Rogier van der Weyden, y posteriormente se expuso como obra de Jan Matsys; y en el Cristo sostenido por Ángeles de los Uffizzi, puede leerse manuscrito "autore tedesco".

16 BOUBLI, Lizzie, 2015, pp. 81-108.

17 HERRERO-CORTELL, M. Ángel; PUIG, Isidro, 2017, pp. 53-78.

18 BOUBLI, Lizzie, 2015, p. 109.

19 Fernando Benito, en 1997, en el catálogo de la exposición dedicada a Vicente Macip había incluido pinturas de Joanes dentro del corpus de obras de su padre, lo que provocó no pocos problemas de atribución. Sin embargo, tras un profuso estudio de la obra de ambos maestros, en el catálogo de la exposición dedicada a Joanes, apena tres años más tarde, esclareció el panorama y fijó una serie de estilemas que, en años posteriores, han servido para ir completando el catálogo pictórico de ambos maestros. Sin embargo, aún en obras recientes de notable relevancia como la de McDonald, se observan los posos de tan desafortunada confusión, al considerar a Macip padre como deudor de Sebastiano del Piombo (McDONALD, Mark, 2012, p. 164), y suponer además su formación en Italia.

20 MCDONALD, Mark, 2018, p. 45.
} 
se minimiza. Los trazos se reducen a los contornos; se trata de dibujos característicamente limpios; encontramos un arcaico grafismo oblicuo a base de líneas cortas y paralelas, componiendo sobrios juegos de luces y sombras, bastante alejados de la potencia expresiva de los dibujos subyacentes joanescos. ${ }^{21} \mathrm{~A}$ tenor de tal ductus, no parece descabellado pensar que los diseños de esta generación de pintores fuesen en sintonía, por ejemplo, con papeles conservados de Lorenzo Costa, Francesco Francia o Cosmè Tura, -con quienes tanto se vincula, por cierto, a Paolo de San Leocadio.22 Incluso, hasta cierto punto, basándonos siempre en sus dibujos subyacentes, la centenaria distancia que los separa del llamado Cuaderno Español de los Uffizi (inv. 2264F-2281F, 18304F-18306F, 18324), ${ }^{23}$ parece no ser tan grande: figuras cuatrocentistas, de cabezas grandes y cuerpos hipotróficos; líneas que se ciñen a los contornos y sombreados oblicuos o a tratteggio.

Por otra parte, continuando con la idea del hipotético débito local ${ }^{24}$-y al margen de influencias iconográficas-, entre el estilo de Fernando Yáñez y el de Joanes hay importantes diferencias en la manera de construir, en el tipo de trazo, la concepción de los volúmenes e incluso el empleo de los materiales. Mientras que Yáñez, por ejemplo, utiliza la punta de plomo -una técnica vetusta, superado el ecuador del $1500-{ }^{25}$ Joanes va a preferir la tinta con eventuales concisiones al lápiz negro o piedra negra, que a menudo combinará con resaltes de albayalde, procedimiento muy habitual ya entrado el siglo XVI. Por tanto, la práctica inexistencia de otros registros gráficos contemporáneos al pintor o directamente anteriores, pertenecientes a un mismo contexto de producción, complica muchísimo una filiación formal metódica. Dicha tara supone que no se puedan establecer vínculos o débitos con los maestros coetáneos o precedentes, -más allá de las limitaciones que presentaría una secuencialización del dibujo subyacente que, no obstante, sí puede ser realizada para la mayoría de obras conservadas de los autores valencianos de la época- ${ }^{26}$

\section{De la primera línea a la última y mancha. La adaptación de la técnica gráfica al propósito del dibujo}

El conjunto de evidencias gráficas de este pintor pone de manifiesto la convivencia de procedimientos diversos, las confluencias de los antedichos débitos internacionales, y sobre todo su capacidad de adecuación a cada registro, lo que demuestra que Joanes era un gran conocedor de los materiales y técnicas de dibujo, plenamente consciente del fin que le reportaba cada tipo de diseño. Solo así puede entenderse su variedad y la divergencia procedimental que demuestra por su capacidad de cambio de registro. ${ }^{27}$ Sin embargo, procedimentalmente, el uso de determinados lenguajes y técnicas lo convierten en un advenedizo artista, -al menos en suelo español-, solo parangonable con esa selección hispana de maestros contemporáneos de los que se tiene constancia documental en Roma o en Italia, durante el segundo y el tercer cuarto del siglo XVI.

Para entender esta disparidad de registros convendría, en realidad, hablar, para mayor precisión, de fases de elaboración y de propósitos. Para ello hay que considerar en cualquier caso el diseño como herramienta y no como fin en sí mismo. Esto implica partir de la premisa de que cada tipo de dibujo responde a necesidades específicas, que condicionan su realidad formal y que generan características inherentes su finalidad, lo que dificulta una confrontación simple entre las diferentes categorías; exactamente la misma inferencia que limita, a su vez, la posibilidad de interrelación entre el dibujo subyacente y el dibujo en papel. ${ }^{28}$

Como herramienta, el dibujo se convierte en el medio más cómodo, directo y rápido para la búsqueda en lenguaje gráfico de la solución que luego devendrá pictórica, en sus diferentes fases. Eso es, dentro del proceso creativo, desde la primera plasmación de la idea -casi con garabatos-, pa-

21 BENITO, Fernando, 2000 a y b; y HERRERO-CORTELL, M. Ángel, 2018 b.

22 El proyecto de clasificación del Gabinetto dei Disegni e delle Stampe delle Gallerie degli Uffizi http://euploos.uffizi.it/inventario-euploos.php

23 MONTERO, 2013, 55-75.

24 BOUBLI, Lizzie, 2015, pp. 81-108.

25 BOUBLI, Lizzie, 2015, p. 66.

${ }^{26}$ Algunos ejemplos pueden encontrarse en: COMPANY, Ximo; PUIG, Isidro, 2010; PUIG, Isidro, 2010, 2013 a y b; PUIG, Isidro; HERRERO-CORTELL, M. Ángel, 2016 y 2017; HERRERO-CORTELL, M. Ángel; PUIG, Isidro, 2017, 2018 a y b; así como en algunas fichas del catálogo de la muestra comisariada por GARRIDO, Carmen; BERTANI, Duilio, 2010.

27 NAVARRETE, Benito, 2016, p. 24.

${ }^{28}$ VAN ASPEREN, Jan, 1985, p. 15. 
sando posteriormente a la evolución del boceto y la progresiva introducción de cambios, hasta la fijación definitiva de la composición y, finalmente, la definición total y estudio final de luces. ${ }^{29} \mathrm{Sin}$ embargo, la presencia de todas estas fases de elaboración del asunto no implica necesariamente su coexistencia, pudiendo ser algunas prescindibles, total, o parcialmente..$^{30}$ Un buen ejemplo de esto es el ciclo de dibujos para el desmembrado retablo de San Esteban (Museo del Prado) que estuvo hasta inicios del siglo XIX en la parroquia homónima de Valencia. ${ }^{31}$ De las seis tablas conservadas del antedicho mueble, existen bocetos de cuatro de ellas, en diversos museos, y pertenecientes a fases diversas del proceso creativo (y probablemente también a fechas muy diversas). ${ }^{32}$

En el reverso del dibujo San Esteban Conducido al Martirio ${ }^{33}$ se aprecia un garabato que, aunque no forma parte de ninguna escena del retablo, constituye la primera plasmación de una idea: el estadio más primigenio de cualquier dibujo; el primer borrón. Aunque no se trata de una figura o una composición relacionada con el antedicho ciclo, sirve someramente como ejemplo para comprender en qué términos lineales viene sintetizada la idea primigenia. Un segundo estadio de plasmación sería el visible en el anverso de la misma hoja, representando el asunto del apresamiento del santo. Se trata de dos variaciones contiguas del tema, que evidenciarían un planteamiento algo más concreto que el estadio anterior. El pintor configura aquí la mayoría de la composición sin entrar en detalle, limitándose a posicionar las figuras, y va introduciendo paulatinamente cambios, sin llegar a precisarlos al detalle en ninguna de las dos variantes. ${ }^{34}$ De hecho, Joanes acabará utilizando figuras y poses de los dos bocetos, e introducirá elementos nuevos todavía no contemplados en ese estadio. El folio de San Esteban acusado de blasfemo (conocido también como Predicación de San Esteban ante el Sanedrín, fig. 1), ${ }^{35}$ podría constituir un ejemplo del tercer nivel, el de la fijación final del modelo, como apunta Boubli (2015, pp. 116-120). Probablemente debido a un cierto volumen de producción y a la participación del taller, es necesario mencionar aquí una cuarta fase, relacionada con la ejecución pictórica. Aunque en la anterior el pintor ha dispuesto todos los elementos de la composición casi al detalle, el estudio tonal no es el definitivo. Precisamente, este cuarto estadio se caracteriza por la utilización de un fondo a mezzatinta, toques de albayalde en resaltes y la mayor depuración de la línea. Son ejemplos de la misma la Santa Cena, ${ }^{36}$ pero muy especialmente la Deposición del cadáver de San Esteban. ${ }^{37}$ Para este tipo de grisallas, en ocasiones, no puede descartarse que se trate incluso de dibujos realizados a posteriori, como testimonio de una obra ya acabada, con fines de registro del modelo para ulteriores copias.

Si el dibujo sobre papel deviene en Joanes notablemente pictórico, mucho más expresivo y gráfico resulta su diseño subyacente, aunque este conforma una categoría muy compleja, que recientemente fue abordada con independencia de las manifestaciones gráficas en pequeño formato, por su complejidad, diversidad y autonomía. ${ }^{38}$ No es el pretexto de este artículo entrar a valorar los diseños que, ocultos bajo los estratos de color, afloran mediante técnicas de análisis óptico en el espectro infrarrojo, y es tan vasto el tema que ha requerido de una publicación específica para el mismo. El formato y el fin de ese tipo de dibujo

\footnotetext{
29 La propia evolución de la obra puede seguir condicionando los ulteriores pasos y, pese a que el artista tenga totalmente configurada en el papel la composición final, algunos elementos pueden cambiar eventualmente, tanto en el dibujo subyacente como en las sucesivas capas pictóricas, estadios en los que es frecuente detectar correcciones y modificaciones.

${ }^{30}$ Un marco conceptual sobre el uso y funciones del dibujo en sus variantes y estadios, y sus diversas categorías puede encontrarse en BOUBLI, Lizzie, 2003.

${ }^{31}$ BENITO, Fernando, 2000 a, pp. 48-158. Véase además sobre ese mismo ciclo: GONZÁLEZ GARCíA, Juan L., 1999, pp. 21-56.

32 La ejecución del retablo duró al menos una quincena de años, desde 1555 a 1570 (PUIG; COMPANY; TOLOSA, 2015, pp. 120124, si es que no duró más como propone BENITO, Fernando, 2000 a, pp. 148-151. Se conservan dibujos relacionados con La predicación de San Esteban ante el Sanedrín; San Esteban conducido al martirio, La deposición del cadáver de San Esteban y la Santa Cena.

${ }^{33}$ Courtauld Institute, Londres, D.1963.WF.4730.

${ }^{34}$ BENITO, Fernando, 2000 a, p. 155, ya evidencia el carácter provisorio de este doble diseño y lo ubica en un estado de concepción anterior al de La predicación de San Esteban ante el Sanedrín.

35 Stocholm Nationalmuseum NMH.1613/1863.

${ }^{36}$ Museo de Bellas Artes de Valencia, inv. 596, $200 \times 420 \mathrm{~mm}$.

37 Gabinetto Disegni e Stampe; Galleria degli Uffizi, Florencia, $8423 \mathrm{~S}$.

38 HERRERO-CORTELL, Miquel A.; PUIG, Isidro, 2018 b.
} 


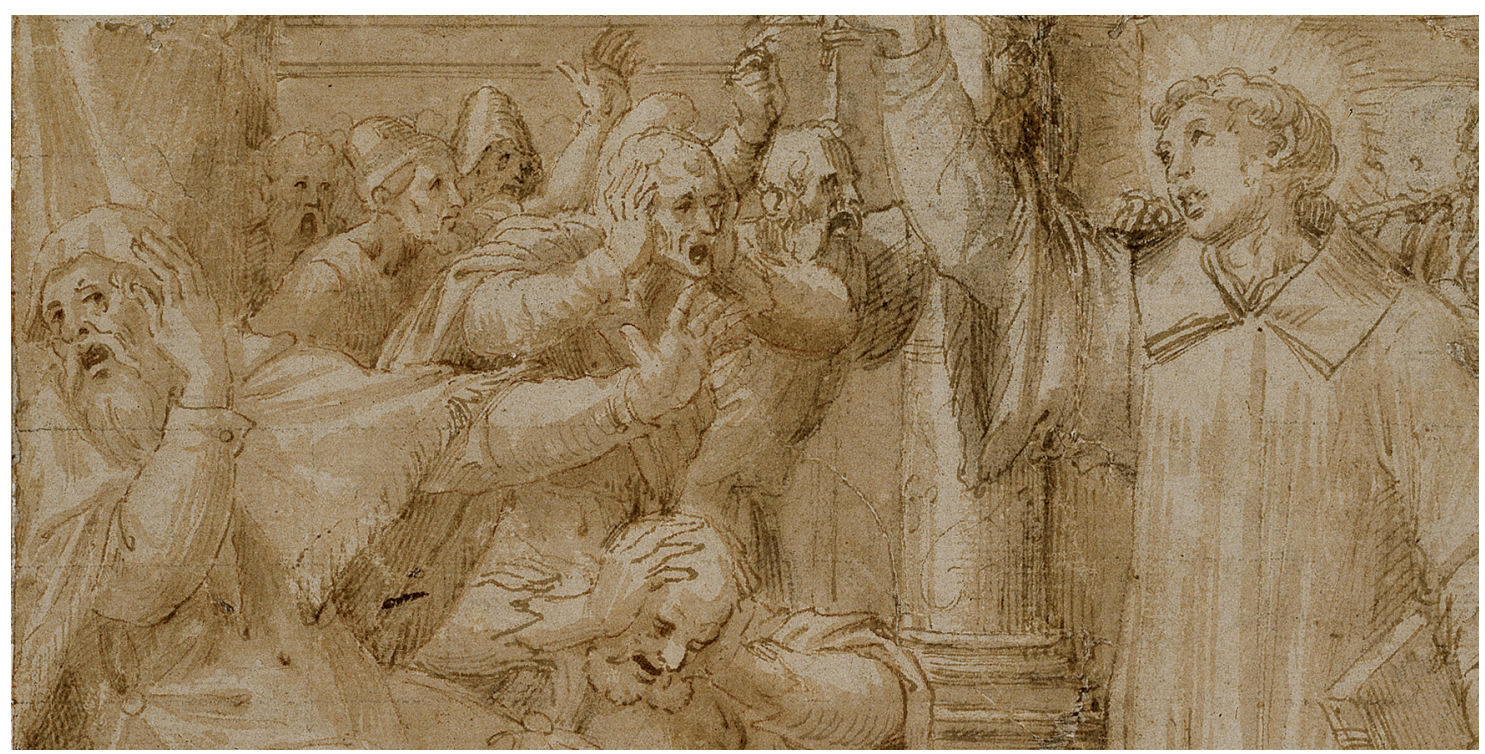

Fig. 1. San Esteban acusado de blasfemo (detalle), Stockholm Nationalmuseum.

determinan un acabado muy diverso (condicionado por la escala, por la ejecución, por las necesidades técnicas del artista en el momento de fijar el diseño sobre la tabla). En realidad, como se ha evidenciado, los dibujos subyacentes del valenciano cumplen un destacado papel en el plano procedimental, y podría decirse que pese a su expresivo grafismo guardan mayor relación con la praxis pictórica que con el limpio trazo que caracteriza algunos de sus papeles. Lo que sí parece evidente es que en los diseños subyacentes Joanes realiza siempre escasísimos cambios y arrepentimientos, lo que claramente indica que, previamente a cualquier ejecución sobre tabla, fijaba todas y cada una de sus composiciones en papel. Por otra parte, el hecho de haber encontrado ejes, cuadrículas y otras evidencias mecánicas de copia en diversos trazados subyacentes nos da idea no solo de cuan fecunda y prolija debió ser la actividad de su obrador en lo alusivo a reutilización de modelos, sino además de lo enormemente dependiente que tal praxis pictórica debía de ser con respecto al dibujo. ${ }^{39}$

\section{Lápiz, pluma y pincel. Las técnicas gráficas sobre papel}

Sobre la técnica de dibujo de Joanes hay todavía bastante que decir. Hasta ahora, solamente unos pocos autores han apuntado eventuales apreciaciones sobre los procedimientos gráficos de los dibujos Joanescos, aunque se echaba en falta un estudio algo más específico sobre el tema. ${ }^{40}$ En realidad se trata, más que de una, de varias técnicas y procedimientos que tienen ecos italianos directos, probablemente adoptados ya desde el inicio de su trayectoria, y que deben emparamentarse con los modos de diseñar típicos de las escuelas romana y florentina. Conviene observar que se trata de demostraciones de una precisión y limpieza tales que presuponen un dominio excepcional del grafismo y todos sus recursos. Esto se observa al confrontar los diversos diseños conservados del artista, muy diferentes entre sí en ocasiones, pero que como ha indicado Navarrete aportan fórmulas empleadas claramente en el mundo italiano, anticipando soluciones que, por lo general, se popularizan en España más tarde. ${ }^{41}$

\footnotetext{
${ }^{39}$ Sin embargo, en todo el repertorio de dibujos conservados del artista, solamente se han conservado trazas del uso de la cuadrícula en el dibujo de San Esteban ante el Sanhedrín. Sobre las evidencias mecánicas en los dibujos subyacentes véase BAMBACH, Carmen, 1999; HERRERO-CORTELL, Miquel A.; PUIG, Isidro, 2018 a; HERRERO-CORTELL, Miquel A., 2018 a.

40 ANGULO, Diego; PÉREZ SANCHEZ, Alfonso E., 1975; BENITO, Fernando, 2000 a; BOUBLI, Lizzie, 2015 y NAVARRETE, Benito, 2016, p. 24.

${ }^{41}$ NAVARRETE, Benito, 2016, p. 381. Así sucede, desde un punto de vista técnico, en los dibujos preparatorios del elenco de pintores que trabajan en El Escorial.
} 
Aunque a veces utilizaba el tono claro del papel (por lo general verjurado), en muchos casos Joanes partía de la mezzatinta tiñendo el papel con una aguada parda o terrosa. En general planteaba las composiciones con sutiles líneas de afiladísima punta de lápiz negro, que reseguía después con una tinta parda, metalogálica, ${ }^{42}$ aunque a veces parece utilizar también una tintura a base de polvo de carbón en suspensión. Al dibujo a pluma, generalmente con trazos rápidos, cortos y sensibles (en el que podía utilizar además tintas en diversos grados de disolución con goma arábiga según le conviniese), le seguía un minucioso estudio de las sombras por adición de veladuras de tinta de mayor intensidad. ${ }^{43}$

\subsection{Borrones lineales}

El borrón o encaje inicial representa un primer intento de aproximación gráfica hacia la idea; un tentativo de formalización lineal del concepto, por lo general realizado con trazos rápidos y muy esquemáticos, como una suerte de organización general compositiva. Sin embargo, puede llegar a diversos grados de desarrollo, acogiéndose a una mayor o menor síntesis, siempre en función de la necesidad del pintor. Por lo general, son escasos los ejemplares de esta tipología que se conservan; casi siempre los más elaborados. Esto sucede porque habida cuenta de su valor exclusivamente funcional y compositivo, muchas veces se trata de ejemplares de escaso interés estético o artístico; prácticamente garabatos, esquemas o apuntes velocísimos que por ser poco inteligibles para quien no los concibe suelen gozar de poco aprecio. Quizás es esta la razón por la que son poquísimos los ejemplos del periodo que se conservan de esta tipología de dibujo, (especialmente cuanto menos figurativos o descriptivos son), si no es porque habitualmente van asociados a cuadernos o a otros dibujos que, por presentar un mayor interés estético, se han llegado hasta nuestros días. Tal es el caso del folio desmembrado con el sujeto de San Esteban Conducido al Martirio, ${ }^{44}$ al que nos hemos referido con anterioridad, y especialmente de su reverso. Tal hoja debía constituir probablemente una página de cuaderno de artista, algo que parece avalarse por el carácter temático heterogéneo de sus contenidos, y especialmente por su carácter funcional, al contener, de hecho, cálculos geométricos e incluso una receta de sisa. ${ }^{45}$

La parte izquierda del verso plantea un boceto ejecutado con tinta metalogálica, sombreado ligeramente con aguadas claras, mientras que en la parte derecha se encuentra otra variante de esta misma composición puramente ejecutada mediante líneas; vibrantes y precisos trazos cortos e incisivos, propios de quien domina, con manifiesta soltura, la pluma. Este tipo de dibujo tiene un fuerte componente expresivo, por el ductus suelto y nervioso que lo caracteriza y por el sensible claroscuro resultante de la superposición lineal y la insistencia en algunas partes. Aunque Navarrete define la línea de Joanes como nítida y con un linealismo casi caligráfico, de clara impronta flamenca -lo que resulta muy acertado para la mayoría de ejemplos-, advierte también que el valenciano es capaz de italianizarse y volverse mucho más expresivo y suelto, con facturas que recuerdan las de los maestros florentinos del final del quattrocento (especialmente de Filippino Lippi y Ghirlandaio), y a los toscanos de las primeras décadas del cinquecento. Así, el estudio de las anatomías varoniles y el carácter histriónico de los sayones poseen fuertes débitos leonardescos, ${ }_{1}^{46}$ pero se rastrean también rasgos de la escuela romana del primer tercio de 1500, (Giulio Romano, Raffaellino del Garbo, Baldassare Peruzzi, Polidoro da Caravaggio y, en general, artistas cercanos a la bottega de Raffaello en sus últimos años de actividad). A los ya observados influjos además añadimos, por nuestra parte, notables ecos de diseños sieneses, emilianos y ferrareses de comienzos de siglo (Bartolomeo Neroni "Il Riccio"; Francesco Francia, y más especialmente su hijo Giacomo Francia; Lorenzo Costa; Pellegrino da Modena; Bartolomeo Ramanghi "Baganacavallo Senior"; o Inocenzo da Imola), que llegan a compartir algunos estilemas, pero que sobre todo permiten una confrontación de registros gráficos que muestra sorprendentes parecidos. ${ }^{47}$

\footnotetext{
42 NAVARRETE, Benito, 2016, p. 381. Sobre las tintas véase: CONTRERAS, Gemma, 2014, pp. 24-33, y 2015.

43 Para un estado de la cuestión sobre las técnicas gráficas y los materiales utilizados véase. HERRERO-CORTELL, Miquel A.; PUIG, Isidro, 2018 b.

${ }^{44}$ Courtauld Institute, Londres, D.1963.WF.4730. GONZÁLEZ GARCÍA, Juan L., 1999.

45 GONZÁlEZ GARCíA, Juan L., 1999, p. 54; y HERRERO-CORTELL, Miquel A., 2018 b.

${ }^{46}$ No podemos dejar de mencionar el comentario del Padre Victoria que aseveraba que Joanes solía visitar morgues y hospitales en busca de cadáveres a los que dibujar en un estudio analítico de la anatomía. MARTínEZ, Jusepe, 1988, pp. 232-234.

47 DI GIAMPAOLO, Mario (ed.), 1989. Sin embargo, no podemos dejar de apuntar dos apreciaciones. En primer lugar, todo este marcado romanismo no puede explicarse desde el influjo de grabados y estampas (principalmente de Marco Antoni Raimondi) como en ocasiones se ha pretendido. Los débitos con el grabador italiano pueden afectar, lógicamente, a lo iconográfico o formal si se desea, pero nunca a lo técnico y procedimental; y en segundo lugar los parecidos con el resto de mencionados artistas emilianos y toscanos no pueden explicarse esta vez, por la circulación de grabados.
} 
Es cierto que la técnica de la pluma, usada para abocetar con soltura, mediante trazos lineales exentos de aguada es un procedimiento en boga desde la Edad Media. Pero el ductus de cada artista es diverso, y el uso que cada uno hace de la plumilla lo convierten en un versátil instrumento capaz de aunar todo un elenco de registros que puede variar mucho. Así se expresa Francisco de Holanda hacia 1550 al referirse a la pluma:48

El segundo instrumento y más noble y dificultoso es con la pluma debujar y echar líneas y perfiles de toda la gravísima sciencia de la Pintura, y esta es la coluna de esta arte; y quien supiere debujar con una pluma, sepa cierto, que no solamente es señor de todos los géneros de la Pintura, más aún de todas las demás sciencias y oficios de este mundo tiene ya sabido la mayor parte ${ }^{49}(\ldots)$. Yo fui el primero que en España debujare con la pluma sin perfil ${ }^{50}$ si no me engaño: mas todavía ya era hallado en italia sin yo saberlo. También hallé en Italia debujar con la pluma anda$\mathrm{da}^{51}$ descendiendo hacia abajo los rasgos todos que es cosa muy dificultosa y mala de hacer, pero son los rasgos que más fuerza tienen y maestría. ${ }^{52}$ También es dulce el debujar con la pluma andada toda hacia una parte sin cruzar nunca los matices..$^{53}$

En realidad, como se argumentaba, los dibujos lineales a pluma en la obra de Joan de Joanes suponen en sí mismos una práctica rareza, al haberse conservado mayormente aquellos en los que el pintor utiliza las aguadas y/o los resaltes. El ejemplo único de esta categoría lo conforma el antedicho dibujo de San Esteban siendo conducido al martirio. El hecho de que se trate de un folio suelto de un cuaderno de taller, y al mismo tiempo la soltura y maestría que caracterizan su ejecución, nos hacen suponer que, en realidad, esta tipología de bocetos de línea suelta y veloz debió ser muy habitual en la producción joanesca.

\subsection{Aguadas descendentes: de la luz a la sombra}

Si importantísima resulta la línea en Joanes -por lo general limpia y precisa-, no menos relevante deviene en sus dibujos la gama de claroscuros que permiten modelar los volúmenes de la forma, así como la incidencia lumínica sobre los mismos. Joanes hace gala de un profundo conocimiento de la luz y su comportamiento sobre las superficies, fundamentado en la observación del natural y en una constante práctica gráfica, que hacen de él un maestro capaz de lograr una alta expresividad con los trazos justos, al tiempo que una alta funcionalidad descriptiva en la definición de las formas. Para ello el pintor explota diversos recursos que contemplan el uso de la sombra, bien a base de trazos oblicuos o bien a base de aguadas de tinta (y ambas a la vez, incluso, en algunos casos), de los que se sirve para modular los gradientes lumínicos. Así, el claroscuro se convierte en un característico recurso del lenguaje joanesco, para el que no desdeña el uso de sutilísimas aguadas de tintas aplicadas reincidentemente, para ir matizando su valor tonal. Tan importante va a ser este recurso en la obra de Joanes que no va a dudar en utilizar soportes coloreados con tintas neutras o mezzetinte y, si procede, resaltes de albayalde, como se verá en el siguiente apartado.

Pero, la característica que define los ejemplares de los que nos ocupamos en este apartado es la ejecución de la luz hacia la sombra, por tanto, partiendo del color claro del papel, que queda reservado para los puntos de máxima luz y gradando los oscuros, a continuación, mediante livianas aguadas de tinta muy diluida. Se trata de un ejercicio constructivo que el autor utiliza en el proceso de creación, antes de la fijación definitiva del modelo.

La aguada es una técnica que puede constituir una adición a un dibujo ya previamente sombreado mediante líneas, lo que sirve para homogeneizar los valores tonales y para diluir en ocasiones la intensidad del trazado, (generando el efecto que se conoce como lavado). A esta primera categoría pertenecen la mitad izquierda del folio conservado en el Courtauld Institute dedicado al tema San

48 DE HOLANDA, Francisco, 2003 [1563] pp. 132-133.

${ }^{49}$ Esta sobrevaloración de la técnica es análoga a la de otros escritos. Lo cierto es que el dibujo con pluma permite escasas rectificaciones y obliga al dibujante a trazos concisos, decididos y directos. Pero lógicamente los procedimientos de dibujo con pluma nada tienen que ver con el color, y se circunscriben, como mucho, al análisis formal, volumétrico y lumínico. Ya CENNI$\mathrm{NI}$, en el capítulo XIII de su obra (1988, p. 44) advierte de que el dominio de la pluma depara maestría; pero, en todo caso, la afirmación de Francisco de Holanda parece entroncar con el gusto de ejercitar ese tipo de dibujo en la época, y el propio Francisco se considera un introductor de una de las técnicas de dibujo a plumilla en España, afirmación que, aunque no sea cierta, se apoya en la escasez de ejemplares con ese tipo de lineamiento. Vid. Nota siguiente.

50 Se refiere a dibujo sin contornear, o lo que es lo mismo, dibujo sombreado.

${ }^{51}$ Esta afirmación queda un poco confusa en el texto; posiblemente se refiera a línea continua.

52 Se refiere a un sombreado en vertical, muy propio de los dibujantes cinquecenttistas.

${ }^{53}$ Aquí se refiere a un sombreado oblicuo, conformado por líneas paralelas, propio también de los maestros de ese siglo, algo comprobable en ciertos dibujos de Leonardo, Miguel Ángel o Rafael, pero también de autores de menor relevancia. 
Esteban conducido al martirio, La predicación de San Esteban ante el Sanedrín, o la traza del Retablo de la Virgen de la Leche (fig. 2), ambos conservados en Estocolmo, en el Nationalmuseum. Por lo general, la incorporación de aguadas y lavados en dibujos de abundante grafismo constituye un recurso estético que ayuda a la comprensión lumínica y tonal del diseño, quedando supeditadas las aguadas a la expresividad de los trazos.

En el caso de la mitad izquierda de San Esteban conducido al martirio, (inv. D.1963.WF.4730, $315 \mathrm{x}$ $217 \mathrm{~mm})^{54}$ se aprecia cómo la concepción inicial del diseño era análoga a la de la mitad derecha del folio: el pintor parte un trazado velocísimo y aplica las aguadas cuando la tinta aún está fresca, provocando ciertos lavados e insiste finalmente con un nuevo trazado de pluma en los puntos en los que desea una mayor penumbra. ${ }^{55}$ Se trata prácticamente de una aguada monocroma -o acaso dosmuy claras, y aplicadas con el pincel medio seco, para evitar una gran descarga de humedad en el papel, tal y como recomienda Cennini en el capítulo $X$ de su libro:

Poi (...) ferma con inchiostro ne' luoghi stremi e necessari. E puoi aombrare le pieghe di acquerella d'inchiostro; cioè acqua quanto un guscio di noce tenessi dentro due goccie d'inchiostro; e aombrare con pennello fatto di code di vaio, mozzetto e squasi sempre asciutto: e così, secondo gli scuri, così annerisce l'acquerella di più gocciole d'inchiostro. ${ }^{56}$

Es en definitiva un recurso más para hacer más inteligible un boceto, cuyo carácter es todavía muy inacabado como sucede para el caso de San Esteban conducido al martirio. ${ }^{57}$ Ligeramente diverso es el sentido de las aguadas en San Esteban ante el Sanedrín y en la muestra del Retablo de la Virgen de la Leche.

En el primero, que también recibe el nombre alternativo de San Esteban acusado de blasfemo ${ }^{58}$ (inv. NMH 1613/1863 59 papel verjurado de color marfil de $330 \times 240 \mathrm{~mm}$ ) en el que por cierto abundan los

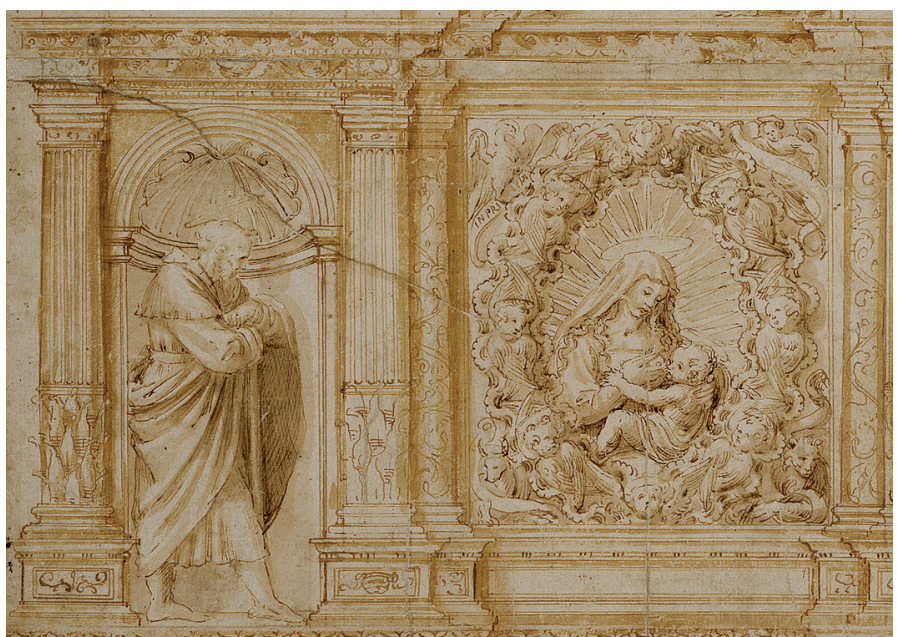

Fig. 2. Retablo de la Virgen (detalle), Stockholm Nationalmuseum.

préstamos formales, ${ }^{60}$ el diseño se constituye como un equilibrio entre trazado y aguada, con predominio de la linealidad y el grafismo sobre la mancha. De hecho, aunque las aguadas van ganando en importancia con respecto al ejemplo anterior, aún se supeditan totalmente al lenguaje de línea. Prueba de ello es que, en ocasiones, los sombreados con estas tintas acuareladas adoptan un tratteggio oblicuo paralelo, una especie de sombreado a base de rayas de aguadas grises. En cierto modo se trata de un trazado de líneas que, aunque están dadas con pincel suave y muy fino, emulan al rayado habitualmente usado para sombrear con la plumilla. Son característicos de este ejemplar, además, una mayor presencia de trazos cortos y discontinuos, de desigual grosor e intensidad, conformando de nuevo líneas sensibles, y el manchado es más expresivo y dinámico. Por último, este diseño incorpora además una cuadrícula, prácticamente invisible, trazada con piedra negra. El hecho de encontrar una cuadrícula trazada sobre el dibujo nos da

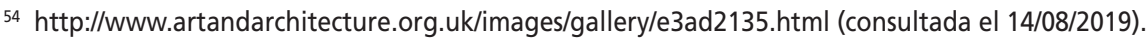

55 Sobre el dibujo en cuestión, véase GONZÁLEZ GARCíA, Juan L., 1999.

${ }^{56}$ CENNINI, Cennino. Cap. X. El modo e l'ordine del disegnare in carta pecorina e in bambagina, e aombrare di acquerelle. Ed. Online: https://www.ilpalio.siena.it///Personaggi/CenninoCennini.

57 BENITO, Fernando, 2000 a, p. 155.

58 ANGULO, Diego; PÉREZ SÁNCHEZ, Alfonso E., 1975, p. 46, lám. L.

${ }^{59} \mathrm{http}: / / \mathrm{emp}$-web-84.zetcom.ch/eMP/eMuseumPlus?service=Externallnterface\&module=collection\&objectld=38680\&viewType=detailView

60 ÁVILA, Ana, 1993, pp. 252-253, ya destaca la presencia de las figuras alegóricas en grisalla, entre las que identifica a Andrómeda; BENITO, Fernando, 2000 a, p. 154, señala los importantes débitos miguelangelescos; por último, Miquel Ángel HerreroCortell señala parecidos en el espacio contextual de la escena con las láminas 269 ilustrada por Palladio para la edición de Daniele Barbaro del tratado de Vitrubio (HERRERO-CORTELL, Miquel A., 2018 b, p. 1337).
} 
una idea del uso de este sistema como herramienta de traspaso y re-escalado de la composición, acaso en un cartón preparatorio, o más probablemente ya sobre el soporte definitivo. ${ }^{61}$ De hecho, se trata de un recurso muy utilizado en el obrador de Joanes y del que, a menudo, aparecen vestigios en los dibujos subyacentes. ${ }^{62}$

El segundo ejemplo es la traza de un retablo dedicado a la Virgen de la Leche, del que nada sabemos. ${ }^{63}$ Boubli ya observó un cierto parecido técnico con el dibujo de San Esteban en el uso de los recursos gráficos. ${ }^{64}$ Esta traza de retablo, conservado en el Stockholm Nationalmuseum (inv. 1614, papel verjurado, 315 x $291 \mathrm{~mm}$ ) es probablemente el mejor ejemplo de "mostra" de retablo del siglo XVI en la Corona de Aragón. Se trata de un dibujo profusamente elaborado, sin llegar a caer en la minuciosidad caligráfica del detalle resuelto, que en cambio sí caracteriza otros ejemplos de su producción. En este caso, más que una profusa descripción de los elementos, los insinúa y sugiere, dando importancia general a todo el conjunto por igual. En este caso el artista utiliza línea de tinta parda dada a pluma y una aguada de la misma a pincel, que aplica de un modo mucho más expresivo que en otros dibujos, simplificando la gama de grises y reduciéndola a los imprescindibles. El manchado lo realiza con fluidez, de un modo muy suelto, resolviendo los gradientes en una escala tonal elevada, ${ }^{65}$ y procurando minimizar los tonos bajos para evitar cualquier competencia con el delineado, que se convierte aquí en el verdadero protagonista. En general puede definirse como una línea limpia y precisa, trazada con regla para las arquitecturas, y discontinua, sinuosa y vibrante y sensible para las figuras. En las zonas de mayor penumbra, en cambio, prefiere recurrir al rayado paralelo y diagonal y no a la mancha, como recurso para los escasos puntos en los que necesita utilizar una escala tonal manifiestamente baja.

Todo este conjunto de características técnicas, a caballo entre la aguada y el trazo suelto ha sido acertadamente puesto en relación con diversos dibujos de Filippino Lippi y de otros pintores tracistas florentinos como Pollaiuolo, Lorenzo di Credi, Piero di Cosimo o Francesco di Simone. ${ }^{66}$ Pero los débitos a Lippi y su entorno, trascienden lo puramente técnico para adentrarse también en lo iconográfico. Boubli67 apunta algunos y recuerda otros que ya habían sido observados por Benito, ${ }^{68}$ como en el Santo Obispo con David, San Bernardo y Moisés (Sir John Soane's Museum, Londres). ${ }^{69}$ También la mandorla que conforma el rompimiento de gloria que flanquea la imagen de la Virgo lactans del centro de la traza puede relacionarse con obras del entorno de Lippi, como San Francisco en la Gloria (Memphis Books Museum, Tennessee). ${ }^{70}$ Por su parte, la figura del arcángel del tondo superior izquierdo se basa de nuevo en un diseño de Raffaellino del Garbo, conservado en el MET (1912, 12.56.5a), basándose en los tondos de Filippino Lippi en el Museo Civico di San Gimignano.. ${ }^{71}$ Por último, se han descrito también algunas influencias de soluciones de libros de arquitectura como I dieci Libri de Arquitectura de Vitrubio, en la edición veneciana de $1556 .^{72}$

Otras veces, en cambio, las aguadas devienen las verdaderas protagonistas en la obra sobre papel del maestro valenciano, minimizando la importancia de la línea, que queda entonces relegada prácticamente a los contornos. En este segundo caso el dibujo se concibe desde el inicio como una acuarela a grisalla, por lo que son siempre las manchas y no las líneas las que deben generar los efectos de

\footnotetext{
61 Sobre el tema véase. HERRERO-CORTELL, Miquel A.; PUIG, Isidro, 2018 a, pp. 12-15.

62 HERRERO-CORTELL, Miquel A.; PUIG, Isidro, 2018 b, pp. 52-54. Sería interesante saber si la imagen infrarroja de la tabla homónima conservada en el Museo del Prado muestra restos de dicha cuadrícula, casi siempre trazada con carbón o con lápiz negro. De lo contrario, cabría la posibilidad de que el diseño fuese reescalado con otro propósito, por ejemplo, para el antedicho cartón, o bien que se hubiese utilizado para cualquier otro fin en el obrador.

${ }^{63}$ MULLER, Priscilla, 1976, pp. 176-180; BENITO, Fernando, 2000 b, p. 192.

64 BOUBLI, Lizzie, 2015, p. 116.

65 En el lenguaje de la praxis artística se denomina "escala tonal" a la gradación de valores entre un tono y otro. Cuando una escala es oscura se denomina baja, mientras que es alta cuando la selección es clara. Véase SMITH, Stan, 1994, pp. 67-71.

66 BOUBLI, Lizzie, 2015, p. 110.

67 BOUBLI, Lizzie, 2015, p. 111.

68 BENITO, Fernando, 1998, p. 54.

69 Véase además GOLDNER, George; BABMACH, Carmen, 1997, pp. 220-221.

70 GOLDNER, George; BABMACH, Carmen, 1997, p. 264.

71 GOLDNER, George; BABMACH, Carmen, 1997, p. 348.

72 HERRERO-CORTELL, Miquel A., 2018 b, p. 1337.
} 
volumen y de sombra apoyándose lo mínimo posible en el trazado. Para las luces se respeta la tonalidad clara del papel, por lo que en general acaban siendo dibujos de característica limpieza, que pierden en grafismo para ganar en pictoricismo, sin que ello, no obstante, afecte a su expresividad.

\section{Decía Cennini al respecto de las agudas:}

Quando hai la pratica nella mano d'aombrare, togli uno pennello mozzetto; e con acquarella d'inchiostro in un vasellino, va' col detto pennello tratteggiando l'andare delle pieghe maestre; e poi va'sfumando, secondo l'andare, lo scuro della piega. E questa tale acquarella vuole essere squasi come acqua poca tinta; e il pennello si vuole essere squasi sempre siccome asciutto; non affrettandoti; a poco poco venire aombrando; sempre ritornando col detto pennello ne' luoghi più scuri. Sai che te ne interviene? che se questa tale acqua è poca tinta, e tu con diletto aombri e senza fretta, el ti viene le tue ombre a modo di un fummo bene sfumate. Abbia a mente di menare il pennello sempre di piatto. Quando se' venuto a perfezione di questo aombrare, togli una gocciola o due d'inchiostro, e metti sopra la detta acquerella, e col detto pennello rimescola bene. $E$ poi al detto modo va' cercando col detto pennello pur nella profondità delle dette pieghe; cercando bene $i$ lor fondamenti. ${ }^{73}$

Las aguadas fueron una técnica de uso común en el dibujo quinientista, muy especialmente en el ámbito romano, aunque común en otros territorios italianos. Si bien es cierto que los manieristas flamencos y holandeses -especialmente los que vivieron un periplo italiano- hicieron un abundante uso de ellas en un modo no muy distinto a como lo hacía Joanes, los ejemplos del uso de esta técnica más en consonancia con las facturas joanescas los encontramos en el ámbito de Rafael, especialmente de la mano de Giulio Romano. Francisco de Holanda se expresaba en estos términos al referirse a las aguadas: "El hacer de aguadas con cualquier sombra sobre papel o pergamino es la sombra de esta arte y toda la invención, y Rafael d'Orbino tuvo en esto su loor". ${ }^{74} \mathrm{~A}$ partir de la segunda mitad del siglo XVI esta técnica experimenta un momento de gran auge que se alargará hasta las centurias siguientes, aunque con manchados mucho más intensos y sueltos que los que realiza
Joanes, cuya precisión gráfica es más descriptiva que expresiva.

En cualquier caso, Joanes es un advenedizo artista usando un modo de hacer que será más afín al de algunos artistas ya de la segunda mitad del siglo XVI. Por ejemplo, este tipo de factura recuerda perfectamente modelos toscanos de finales de la centuria, como el del dibujo preparatorio de Romulo Cincinato para la Cena Pascual (1589) Uffizi 14389 F, en el que el artista deja fluir las aguadas consiguiendo un gran pictoricismo en los pliegues. ${ }^{75}$

Tres son los ejemplos más ilustrativos de esta modalidad técnica, al que se le añade un cuarto que del que no descartamos que pueda tratarse de un diseño de taller (quizás a alguno de sus hijos, aunque con las reservas de no haber podido contemplar el dibujo de cerca), y un quinto que, como mínimo, requiere un estudio en profundidad antes de la emisión de cualquier juicio.

El primero de ellos es un San Sebastián que se encuentra depositado en la Real Casa de la Moneda $(215 \times 111 \mathrm{~mm}) .^{76}$ Es este, sin duda, uno de los mejores ejemplos del virtuosismo gráfico de Joanes. El tratamiento anatómico es preciso y veraz, con ciertas concesiones a la hipertrofia muscular propia del cinqueccento romano, acusando una gran influencia del dibujo piombesco. Esta cierta rotundidad de las formas se aleja de los prototipos de la centuria anterior, que suelen presentar volúmenes mucho más livianos, en los que la insinuación de los músculos resulta mucho menos destacada. El interés por la correcta anatomía de Joan de Joanes, y su obsesión por el dibujo del natural ya fue descrito por Jusepe Martínez, y este diseño da buena cuenta de ello. ${ }^{77}$ El modelo esta vez, debió ser una obra de la escuela emiliana, o acaso ferraresa, puesto que se conserva en los Uffizi un San Sebastián (inv. 8542-1890) cuya posición es idéntica, inspirado a su vez en un diseño de Ercole de'Roberti. ${ }^{78}$ Para este tipo de diseño el pintor sigue siempre un mismo proceso, que hemos descompuesto y analizado (fig. 3). Embasta la figura con trazos finos de plumilla, con tinta parda. A continuación, emprende un estudio lumínico-volumétrico a base de manchas, mediante un sutil som-

\footnotetext{
73 CENNINI, Cennino. Cap. XXXI. "Come tu dèi disegnare e aombrare in carta tinta di acquerelle, e poi biancheggiare con biacca". Edición online en: https://www.ilpalio.siena.it/5/Personaggi/CenninoCennini?R=31

74 DE HOLANDA, Francisco, 2003 [1563], p. 133.

75 NAVARRETE, Benito, 2016, pp. 114-115.

76 BENITO, Fernando, 2000 a, p. 111.

77 MARTÍNEZ, Jusepe, 2008 [1672], p. 275.

$78 \mathrm{http} / / /$ catalogo.fondazionezeri.unibo.it/scheda/opera/31745/Roberti\%20Ercole $\% 20$ de $\% 27 \% 2$ C\%20San \%20Sebastiano
} 

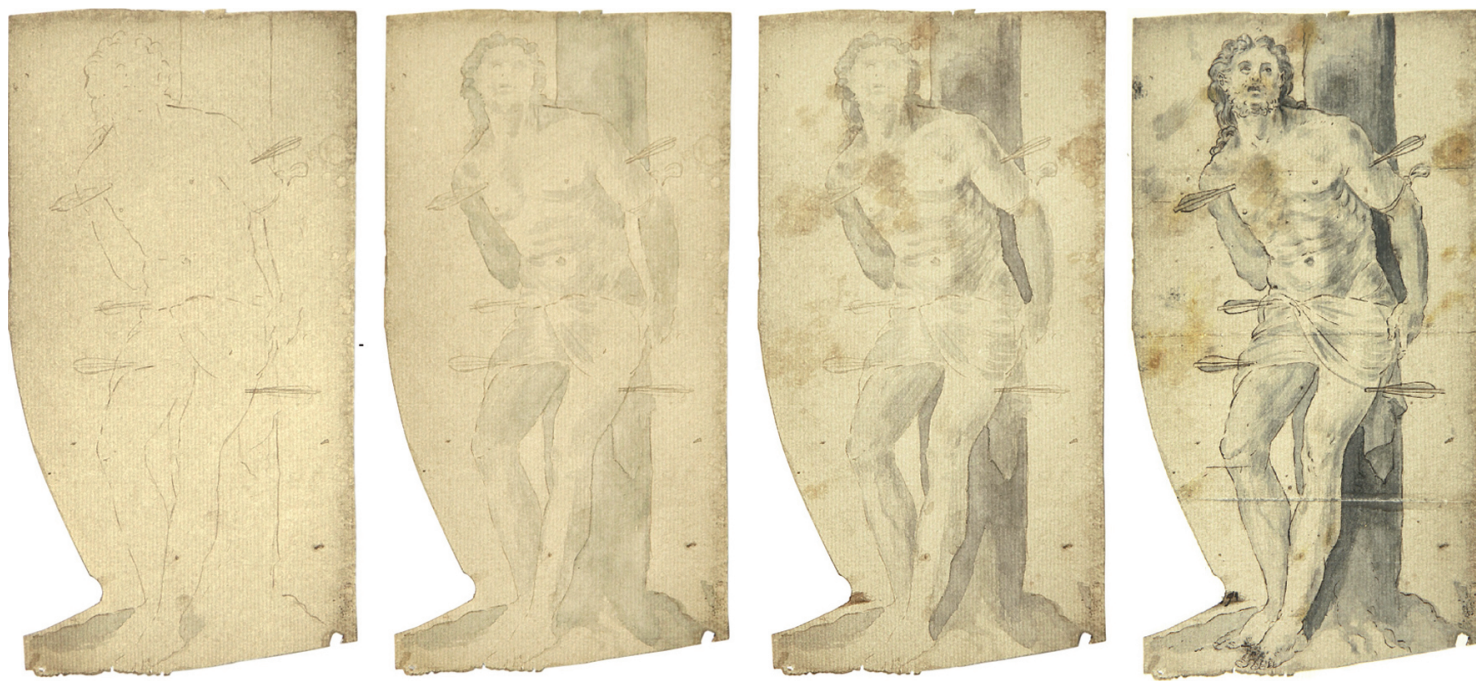

Fig. 3. Reconstrucción del proceso de creación del San Sebastián de la Real Casa de la Moneda.

breado en una escala tonal elevada, que ejecuta con una tinta de un color mucho más grisáceo, presumiblemente a base de carbón. Este manchado se configura mediante aguadas livianas de tintas, que van tomando fuerza por insistencia, por superposición de capas, como sugería Cennini.

El segundo de los modelos es un Estudio de figura femenina (¿acaso una alegoría?), que apareció en mercado internacional, y que fue subastado en Christie's, el 5 de julio de 2005 (lote 3, venta 7066). ${ }^{79}$ Se trata de un dibujo bastante deteriorado, realizado sobre papel color marfil, de 192 × $90 \mathrm{~mm}$, que presenta una limpísima factura, muy en línea con el ejemplo anterior. A pesar del sutil erosionado de la superficie, la calidad técnica que subyace pone de manifiesto hechuras similares a las del antedicho San Sebastián, con finísimos drapeados solucionados con matices de grises claros. De hecho, en el propio catálogo de la subasta se indicaba: "The drawing closest in handling to the present sheet is a Saint Sebastian in the Casa de la Modena [sic.] in Madrid (...). It shows the same handling of the pen in short strokes combined with a very smooth application of wash". A pesar de que no se ha podido identificar por el momento la figura con ninguna obra de Joanes, tanto los estilemas como el lenguaje la hacen fácilmente adscribible a su corpus y, por su calidad, plantea pocas dudas en cuanto a su atribución, a pesar de su discreto deterioro.

El tercer caso es el San Vicente Ferrer, conservado en el Museo de Bellas Artes de Valencia. (inv. 4234). ${ }^{80}$ El dibujo está ejecutado sobre papel verjurado, a una sola tinta, con gran economía de líneas, que aparecen como los característicos trazos cortos y discontinuos. El sombreado está elaborado a base de mórbidas aguadas que podrían ser el resultado de un posterior lavado. La figura tiene un cierto hieratismo que la relaciona con modelos de finales del quattrocento italiano, como algunos santos de Bartolomeo Neroni, igualmente enjutos de hombros, y de arcaica postura. ${ }^{81}$ La ejecución es limpia, con un manchado muy difuminado en una escala tonal media-alta, rica en matices cromáticos, y en la que el manchado se funde a la perfección.

El cuarto ejemplo es un Ángel con atributos de la pasión, es quizás el más lineal de esta tipología. ${ }^{82}$ Se trata de un dibujo a plumilla con aguadas sepias, sobre papel agarbanzado verjurado de 29,8 x $18,9 \mathrm{~cm}$ (fig. 4). Fue vendido en Alcalá Subastas

\footnotetext{
79 https://www.christies.com/lotfinder/Lot/juan-macip-called-juan-de-juanes-valencia-4539331-details.aspx (Consultado el 20/03/2019).

80 BENITO, Fernando, 2000 a, p. 176; ESPINÓS, Adela, 1979, p. 16. n. 2.

81 Véase por ejemplo, la predela subastada en 2015: https://www.the-saleroom.com/en-us/auction-catalogues/pandolfini-casadaste/catalogue-id-srpan10015/lot-8b0fb329-d747-401c-8066-a54700db320d

${ }^{82}$ ANSÓN, Arturo; CENTELLAS, Ricardo (com.), 2008, p.94-97, n.3.
} 
(n. 83, lote 213). ${ }^{83}$ Los estilemas, algo exagerados, la sutil desproporción del torso y los brazos, y el drapeado, menos estudiado y naturalista que otros ejemplos, nos inducen a pensar en una obra tardía del pintor, o más verosímilmente en una obra del taller ejecutada bajo su supervisión, quizás por alguno de sus hijos. De hecho, la figura presenta análogas proporciones y estilemas a las de los Ángeles Turiferarios, del museo de Bellas Artes de Álava, considerados tanto por Albi como por Benito como obra de Vicente Joanes. ${ }^{84}$

El quinto, de atribución dudosa, es un dibujo con la Trinidad conservado en el Monasterio del Santo Espíritu de Gilet, que recientemente fue considerado como dibujo de Joanes, pese a que tradicionalmente había sido tenido como obra del Beato Nicolau Factor, como reza una inscripción al pie del diseño. ${ }^{85}$ Se trata de un dibujo sobre pergamino (algo nada común en la obra joanesca), que parece ilustrar una página de un antifonario. Ciertamente es un ejemplar en el que predomina la aguada sobre la línea, conviviendo con elementos propios de la miniatura monástica. En palabras de Fray José M. Barrachina: "Es un dibujo en color sepia e iluminado a la cola con colores desleídos en agua goma, pintado sobre pergamino de una página de Liber Chori, pues lleva anotación gregoriana en el reverso. Parece una letra capital, la $\mathrm{C}$, llamativamente iluminada" ${ }^{86}$ A priori observamos algunas discrepancias en el modo de elaborar los drapeados y pliegues de la túnica, al tiempo que advertimos algunos fallos de encaje en los brazos de Dios Padre. Todo ello, sumado al desconocimiento de la obra de Nicolau Factor, -que se sabe discípulo directo de Joan de Joanes y del que no se tiene certeza de ninguna pintura-, nos hacen mantener una actitud prudente al respecto y considerar como hipotéticamente correcta la atribución al Beato Nicolau. Es cierto que las caras profesan estilemas joanescos, pero a falta de un estudio de mayor profundidad, y sin haber podido contemplar el dibujo de cerca, preferimos dejar el asunto abierto.

\subsection{Aguadas ascendentes: de la sombra la luz. Tinta y albayalde}

La última de las tipologías técnicas usadas por Joanes es quizás la más representativa del pintor, y también la más documentada. Mientras que el

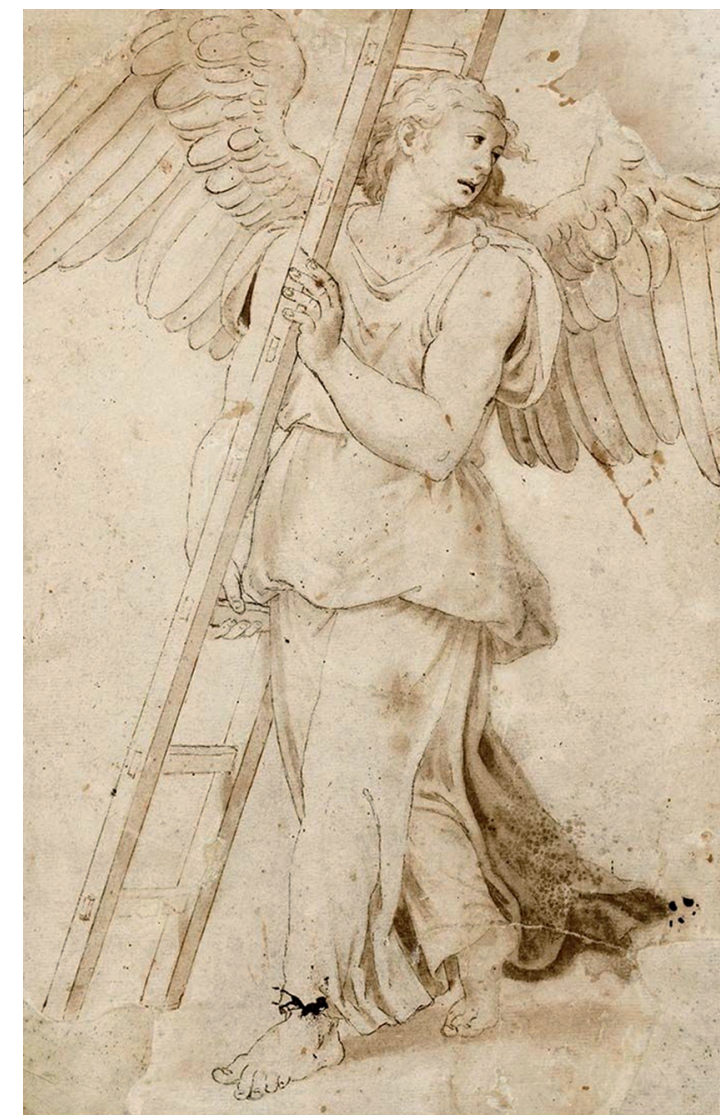

Fig. 4. Ángel con atributos de la pasión (detalle), Colección particular.

artista utiliza el dibujo substractivo (de la luz del papel a la sombra de la aguada) para construir, como se ha visto, prefiere el dibujo aditivo (de la sombra a la luz), para fijar sus composiciones, partiendo, casi siempre, de un valor tonal medio que produce tiñendo el papel con tinta o pigmentos. Con este efecto homogeniza una luz media imperante, que gradará hacia oscuros con tinta. En cambio, para los claros, al no poder contar con la reserva del tono del papel, las luces debían ser ejecutadas, como las sombras, por adición de un color más claro -por lo general albayalde aglutinado con goma-, lo que permitía al pintor un detallado estudio lumínico directamente relacionado con su modo de pintar. Pero antes de adentrarnos en una explicación procedimental y técnica

\footnotetext{
${ }^{83} \mathrm{https://www.alcalasubastas.es/cn/subastas/46-57734/juan-macip-Ilamado-juan-de-juanes-h-1505-1579-ngel-con-arma-chris-}$ ti-h-1550

${ }^{84}$ ALBI, José, 1979, tomo II, p. 451. También BENITO, Fernando, 2000 a, p. 253, comparte la mencionada atribución.

85 GÓMEZ ARRIBAS, Antonio, 2014.

${ }^{86}$ BARRACHINA, José M., 2003, p. 28.
} 
conviene mencionar que este modo de dibujar con papel coloreado era ya conocido desde la Edad Media. De nuevo Cennini nos reporta en el capítulo XV sobre el modo de dibujar sobre papel teñido. ${ }^{87}$ Pero quizás los capítulos más adecuados a la descripción de esta técnica sean el XV, el XXXI y el XXXII. ${ }^{88}$ En el XXXI se precisa cómo dar las aguadas de albayalde:

(...) Quando hai fatto così, togli uno poco di biacca ben triata con gomma arabica (...). Ogni poca biacca basta. Abbi in uno vasellino acqua chiara, e intignivi dentro il pennello tuo detto di sopra, e fregalo su per questa biacca macinata del vasellino, massimamente s'ella fusse risecca. (...). Poi, in sulle stremità de' rilievi, nella maggiore altezza, togli un pennello con punta; e va' colla biacca toccando colla punta del detto pennello, e va' raffermando la sommità de' detti bianchetti. (...).

La técnica, en realidad, es muy propia de finales del $\mathrm{XV}$, y sobre todo del siglo $\mathrm{XVI}$, si bien perduró con gran arraigo durante la siguiente centuria. Fueron muchos los artistas que usaron las aguadas sobre carta tinta, utilizando además resaltes de albayalde para las luces. La técnica se popularizó entre los artistas florentinos y flamencos, alcanzando una gran aceptación durante la segunda mitad del siglo XVI. Pero lo cierto es que no todos la usaron de un modo análogo; y el sentido de las aguadas y los resaltes de albayalde podía responder a un simple efecto, a un estudio lumínico, o a un estudio lumínico-pictórico, como sucede en el caso de Joan de Joanes. Es una manera muy similar de trabajar a la que presenta, por ejemplo Pedro de Campaña, que según las investigaciones debió realizar un cierto aprendizaje en Roma lo que marcaría un cierto estilo con importantes débitos hacia lo italiano, visible en dibujos como San Jorge y el Dragón (Museo de la Casa de la Moneda de Madrid), o la Crucifixión de los Uffizi. ${ }^{89}$ Se trata de un tipo de dibujo que comparte con Joanes y que el bruse- lense debió consolidar durante su estancia en Roma en la década de 1530. La influencia de sombrear con aguadas y realzar con albayalde será fundamental para los pintores sevillanos del último tercio del siglo XVI, influyendo notablemente en autores como Pacheco o Velázquez. ${ }^{90}$

Precisamente, no parece casual que esta técnica esté ligada a la cuarta fase de trabajo, la del estudio final de las luces, o, incluso a una fase de ulterior registro del modelo. En cambio, en fases compositivas, creativas o constructivas el valenciano no usa el realce de albayalde. De hecho, la elección de esta metodología entronca con el modo de pintar de Joanes: los puntos en los que en los dibujos se aprecia un uso de carbonato de plomo equivalen a los puntos en los que en la pintura se dispondrán las grandes masas de este mismo pigmento. Joanes utiliza una construcción de empastes de blanco de plomo sobre la capa de sulfato de cal, en las zonas en las que luego habrá luces, en drapeados y carnaciones. Posteriormente, mediante la adición de capas de color, irá velando dichas luces hasta que queden adecuadamente matizadas e integradas. ${ }^{91}$ En este sentido, el dibujo se convierte aquí en una herramienta instrumental para guiar la participación del taller, al tiempo que probablemente sirve como registro de la obra; un modelo de gran utilidad para percibir el volumen y la construcción lumínica de las figuras, e incluso una plantilla para entender dónde ubicar las masas de blanco de plomo. Una guía misma para ejecución de un determinado modelo, que probablemente permanecería en el obrador para ser reutilizado si se daba el caso. Diversos son los ejemplos que pertenecen a esta categoría. Los tres de mayor calidad son La Santa Cena (fig. 5) del Museo de Bellas Artes de Valencia; La deposición del cadáver de San Esteban, y el Cristo Muerto, sostenido por Ángeles, ambos en el Gabinetto dei Disegni e delle Stampe degli Uffizi.

\footnotetext{
87 "Per venire a luce di grado in grado, e incominciare a volere trovare il principio e la porta del colorire, vuolsi pigliare altro modo di disegnare che quello di che abbiamo detto perfino a mo. E questo si chiama disegnare in carta tinta; cioè o in carta pecorina, o in carta bambagina. Sieno elleno tinte; però che in una medesima forma si tinge l'una che l'altra, e d'una medesima tempera. E puoi fare le tue tinte o in rossetta, o in biffo, o in verde; o azzurrine, o berrettine cioè colore bigie, o incarnate, o come ti piace; ché tutte vogliono medesime tempere, e medesimo tempo a macinare colori; e in tutte per un medesimo modo si può disegnare. È vero che la tinta verde comunemente per la più gente si usa più e più, ed è più comunale sì per l'aombrare e si per lo imbiancheggiare: benché più innanzi dichiarerone ogni triare di colori, e loro natura, e loro tempere. In brieve, qui ti darò un brieve modo, per lo bisogno che hai a venire al tuo disegnare, e del tuo tingere delle carte". CENNINI, Cennino. Cap. XV. Come dèi pervenire al disegno in carta tinta.

${ }^{88}$ Cap. XXXI. Come tu dèi disegnare e aombrare in carta tinta di acquerelle, e poi biancheggiare con biacca; Cap. XXXII. Come tu puoi biancheggiare di acquarelle di biacca, si come aombri di acquarelle d'inchiostro.

89 Véase DACOS, Nicole, 2012, p. 31 y 77.

90 NAVARRETE, Benito, 2016, pp. 302-304.

91 La técnica pictórica del valenciano requiere de un estudio especializado en el que en la actualidad nos encontramos trabajando, demasiado complejo y extenso como para tener cabida en este texto.
} 
La Santa Cena del Museo de Bellas Artes de Valencia (inv. 596), es quizás uno de los mejores ejemplos de esta tipología. Se trata en este caso de un dibujo preparatorio que era, a su vez, un estudio lumínico y volumétrico para la realización de la tabla homónima conservada en el Museo del Prado, que también formaba parte del retablo de San Esteban. En este caso el diseño se elaboró como detalladísima grisalla antes de la realización de la mencionada pintura. Como observa Benito, al adaptar el diseño al tablero, tuvo que comprimir ligeramente la composición para adecuarse al formato lígneo, acercando y solapando las figuras mediante un efecto de traslapo. ${ }^{92}$ Se trata de un dibujo ejecutado sobre un papel verjurado teñido de un color pardo; quizás mediante una disolución de tinta metalogálica. Conformando las aguadas se advierten al menos dos tipos de tinta, -como sucedía también en el San Sebastián-; una de más oscura color grisáceo-negruzco, acaso por ser de carbón, usada en los drapeados de los cortinajes, en el suelo y en los fondos, y otra para el resto de sombreados, de tonalidad un poco más rojiza, que además parece ser similar a la utilizada para la tinción del papel. Además, se suman trazados en piedra sanguina y restos de lápiz negro. A pesar de la notable erosión superficial, de las abundantes lagunas y del intenso teñido del soporte, se aprecian perfectamente los sutiles juegos de sombras acuareladas en pliegues y rostros. Estas aguadas comparten protagonismo con caligráficas líneas, -precisas y seguras, circunscritas a los contornos sin escatimar en detalles-, y sobre todo con los modulados resaltes de albayalde que describen cada volumen, cada protuberancia anatómica, y cada arruga de los drapeados, con milimétrica profusión, pese al reducido formato del papel. El diseño debió quedar como modelo de obrador, puesto que fue reutilizado con posterioridad por Vicente Macip, quien -según Benito-, "dadas sus limitaciones, lo rayó con una cuadrícula para poder transportarlo con fidelidad" durante la realización de la Santa Cena conservada en ese mismo museo. ${ }^{93}$ La obra, que adquirida en 1996 como autógrafa de Vicente Macip Comes, muestra una calidad excepcional, a pesar de no encontrarse en muy buenas condiciones de conservación.

Mucho mejor estado presenta en cambio el Entierro de San Esteban (Uffizi, 8423 S, 358 x 275 mm),

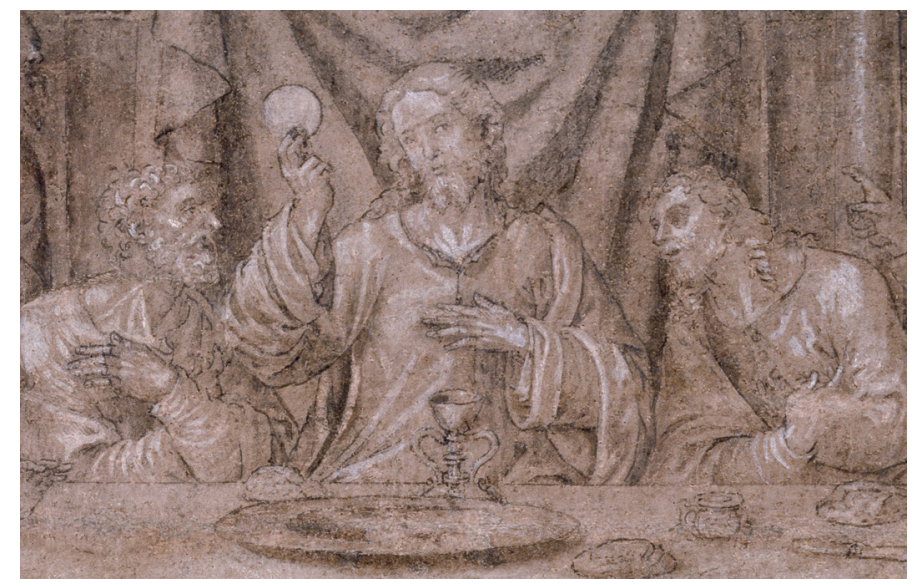

Fig. 5. Santa Cena (detalle), Museo de Bellas Artes de Valencia.

otro de los ejemplos clave de esta tipología. ${ }^{94} \mathrm{~A}$ diferencia del anterior, el dibujo corresponde a una postrera fase de fijación del modelo, y debió ejecutarse después de la finalización (o al menos durante la realización) de la pintura homónima, quedando directamente como registro de taller, lo que explica, por una parte, su factura algo más atada. A pesar del carácter inacabado (análogo al de tantos otros diseños joanescos) la total dependencia formal del dibujo para con la pintura evidencia precisamente esta realización póstuma. Es poco probable que, durante la realización de la tabla la obediencia al dibujo -en cada pliegue, en cada arruga, en cada detalle-, pueda mantenerse; más bien parece lógico que sea justo a la inversa. Aspectos como el paisaje del fondo, el perfil de las montañas, las colinas, o las ruinas, cuyo carácter es meramente estético, son susceptibles de modificaciones en el curso de la ejecución pictórica -como se observa en el resto de ejemplos de esta misma serie- $y$, en cambio, mantendrían una total fieldad con un dibujo de pequeñas proporciones, lo cual parece poco probable. Incluso el siIlarejo escuadrado en el ángulo inferior izquierdo -un elemento descontextualizado, ubicado allí con la única pretensión de incorporar el escudo de los Aguiló-, aparece en el dibujo, aunque se prescinde del motivo heráldico, precisamente porque había de quedar como muestra de taller. Pero, volviendo a la apariencia formal del diseño, el pro-

\footnotetext{
92 BENITO, Fernando, 2000 a, p. 160.

93 BENITO, Fernando, 2000 a, p. 160.

94 Todo el estado de la cuestión bibliográfica se puede consultar en: NAVARRETE, Benito, 2016, p. 382.
} 
pio Benito advertía "una factura más evolucionada con respecto al ejemplar de Estocolmo", ${ }^{95} \mathrm{y}$ Navarrete, por su parte, admitía que, así como el de Estocolmo y el de Courtauld son mucho más nerviosos en el trazo, más veloces y más frescos, este es algo más atado, pero sigue siendo uno de los más bellos del conjunto. ${ }^{96}$ La razón es siempre el antedicho estatus del dibujo y su carácter de muestra de atelier. De marcado pictoricismo, la factura detallista, tanto en línea como en calidad de la grisalla, remite a la inequívoca mano del maestro, cuya capacidad de cambio de registro queda plasmada en la expresividad lograda en los histriónicos personajes, que una vez indujeron a error en su atribución, proponiendo para su autoría la mano de Jan Matssys. ${ }^{97}$ Sin embargo, pese a que, como se ha dicho, los manieristas flamencos usaron ampliamente esta técnica de aguadas y resaltes de albayalde, la ejecución del dibujo guarda importantes analogías con el diseño florentino del momento..$^{98}$

El Cristo muerto sostenido por dos ángeles (Uffizi, $8884 \mathrm{~S} 254 \times 198 \mathrm{~mm}$ ) ${ }^{99}$ constituye un tercer exponente de esta serie, de análoga calidad, fue recientemente descubierto y atribuido por Benito Navarrete. Se trata de un dibujo efectuado con lápiz negro, pluma de tinta parda y negra y leves toques de albayalde sobre un papel verjurado ligeramente teñido a mezzatinta con un color ambarino-pardo, características técnicas que, como se evidencia, comparte con otros dibujos del mismo autor. ${ }^{100}$ En este caso utiliza el lápiz negro para delinear sutilmente los contornos, para luego fijarlos en algunos puntos con una tinta parda, a través de ligeros toques. El autor prescinde en la medida de lo posible de las líneas, que nuevamente se relegan a contornos, lo que realza el carácter pictórico del diseño. Particularmente delicado resulta el modo de modelar las anatomías, utilizando una escala tonal muy elevada, que solo desciende para los paños, algo similar a lo que acaecía con otros ejemplares en los que el sutilísimo juego de aguadas devenía el protagonista. Habida cuenta de la regular conservación del dibujo, es posible que este contuviese muchos más toques de albayalde, resaltes y luces que se han ido desprendiendo, como sucede en el resto de casos, quedando vestigios de las mismos solo en los rostros y algún que otro punto eventual. Sin embargo, conviene también apuntar que debe tratarse con casi toda probabilidad de un dibujo inconcluso, -como tan acertadamente apunta Navarrete- (quizás uno de los menos acabados, de acuerdo con la riqueza del planteamiento y la escala de la composición), aunque es cierto que casi toda la producción gráfica joanesca tiene un cierto carácter de non finito. ${ }^{101}$ La reserva rectangular superior -en el espacio en que se dispondría Dios Padre-, así como la escasa superposición de tintas en muchos puntos, y la ausencia total de vestigios de albayalde en la mayoría de zonas, ${ }^{102}$ parecen razones fundamentadas para avalar el estado de inconclusión del diseño, que probablemente se date ya en la última década de producción del maestro valenciano. Aunque parece que el tipo iconográfico podría deberse a Marco Antonio Raimondi, ${ }^{103}$ este tiene de nuevo como probable precedente a Lippi. De hecho, se advierte un claro paralelismo con la Piedad con San Antonio y San Pablo Ermitaño y un Ángel, depositado en el Musée de Beaux-Arts de Lyon (1966375). ${ }^{104} \mathrm{El}$ hallazgo de este folio supuso el reconocimiento de una pieza fundamental para el estudio de la producción gráfica de Joanes, pero también otra importante evidencia para la confirmación de la técnica de diseño del maestro valenciano, y para el estudio de la misma, al tratarse de un dibujo inconcluso. ${ }^{105}$

Hay otros dos ejemplos de dibujos, dedicados no a composiciones, como los anteriores, sino a figuras

\footnotetext{
95 BENITO, Fernando, 2000 a, p. 158.

${ }_{96}$ NAVARRETE, Benito, 2016, p. 382.

97 En 1947, el dibujo se exhibió en una exposición dedicada al arte flamenco en el Palazzo Strozzi como obra de Jan Matsys (1509-1575). RAGGHIANTI, Carlo L., 1948, p. 64, n. 29.

${ }_{98}$ NAVARRETE, Benito, 2016, p. 382.

${ }^{99} \mathrm{http}: / /$ euploos.uffizi.it/scheda-catalogo.php?invn=8884+S

100 NAVARRETE, Benito, 2016, p. 384 y 386.

101 NAVARRETE, Benito, 2016, p. 384.

102 Aunque los toques de albayalde se pierdan por erosión o fricción, o bien por lavado, suelen dejar una serie de vestigios, a modo de cercos o manchas que se documentan con frecuencia, por ejemplo, en el resto de ejemplares, y que en este caso no se dan, lo que efectivamente sugiere que en muchos puntos nunca llegaron a existir dichos resaltes.

103 BENITO, Fernando, 1993, p. 21 y BENITO, Fernando, 2000 a, pp. 82-83, 192 y 222.

104 GOLDNER, George; BABMACH, Carmen, 1997, pp. 282-283.

105 NAVARRETE, Benito, 2016, p. 18.
} 
exentas, que tienen la particularidad de estar realizados sobre papel teñido de almagra, una moda que ya recoge Cennini cuando habla de la tinción del papel y que, de hecho, se constata como una moda en los últimos años del siglo XV y en los primeros del siglo XVI. El primero de ellos es una Santa María Magdalena al pie de la Cruz (D003052, $220 \times 175 \mathrm{~mm}$ ). ${ }^{106}$ Aunque probablemente deba tratarse de un modelo pensado para restar en el taller, la calidad de la ejecución, facilita la atribución a Joanes. Es posible que la figura de María Magdalena fuese diseñada para una crucifixión que no ha llegado hasta nosotros, a pesar de que muestra parecidos formales con la Magdalena del Calvario del retablo de Cristo de la parroquia de San Nicolás y San Pedro Mártir de Valencia, y más con la Magdalena del Tríptico de la Crucifixión (inv. 536) del Museo de Bellas Artes de Valencia, con la que coincide en la posición de rostro y en la inclinación y cadencia del manto. ${ }^{107}$ El modelo muestra sorprendente parecido con una Santa María de Filippino Lippi, en el British Museum (1895, 0915.442, 307 x $16 \mathrm{~mm}$ ) también sobre papel almagra con resaltes de albayalde. ${ }^{108}$ Técnicamente se trata de un ejemplar de gran interés, pues además de estar bien conservado permite, por el contraste con el rojo del fondo, apreciar la calidad de las aguadas de tinta y los realces de blanco de plomo. El pintor parte de una pieza de papel verjurado -como en el resto de su producción-, que tiñe de almagra con un baño en una agua-cola que contiene la dispersión de tal pigmento. Una vez seco encaja con un lápiz negro, apenas perceptible, los ejes compositivos de la figura, y a continuación señala con finísimos toques de tinta los principales trazos casi siempre ciñéndose a los contornos. Emprende entonces un estudio de sombras, añadiendo numerosas aguadas de tinta metalogálica en disolución acuosa, sobre las que reincide diversas veces en función del gradiente de oscuridad deseado. Por último, templa un poco de albayalde en agua-cola o en una disolución de goma arábiga, y repite la operación, realizando gradientes de blanco sobre los que señala con el pigmento casi puro las máximas luces.
Para una mejor comprensión visual del proceso se ha reconstruido en tres pasos (fig. 6).

El otro ejemplo es una figura de Cardenal, en colección particular en Barcelona, que sirvió como modelo del personaje homónimo en la tabla de la Aparición de San Miguel en Castel Sant'Angelo, del Retablo de San Miguel del gremio de Pelaires. Se trata de un estudio de drapeados muy básico de la caída de la capa cardenalicia. Tanto las aguadas como el albayalde están dados con cierta premura, sin insistir demasiado en la transición de los gradientes. Por su simplicidad y por lo limitado de su calidad técnica, constituye uno de los ejemplos más discretos del pintor (sin poder descartar que se trate de un folio de taller). Fernando Benito ya reconoció que las características formales de este diseño se aproximaban a la Virgen Sendente del Museo del Prado, obra de la que a continuación nos ocuparemos. ${ }^{109}$

Por lo que respecta a la Virgen Sedente (Museo del Prado, D0000II, 285 x $185 \mathrm{~mm}$ ), se trata de un folio que evidencia una notable menor calidad $y$ soltura, por lo que parece más adecuado adscribirlo a otra mano. Es posible que se trate en realidad de un ejercicio de bottega, ${ }^{110}$ o incluso de la copia de un patrón, una suerte de repetición modelo de reportorio de taller, frecuente en los obradores del Renacimiento. ${ }^{111}$ Podría considerarse un estudio en grisalla de la figura (o del drapeado) de la Virgen, utilizando un papel teñido como tono medio neutro, al que se superponen sombras a base de aguadas de diversas intensidades. Un análisis del ductus y del trazo lo acerca de inmediato a su entorno directo o indirecto. Los sombreados con aguadas de tinta son poco mórbidos e imprecisos, dubitativos y faltos de seguridad, evidenciando la ausencia de la finura que caracteriza los drapeados de la mano de Joanes. Los resaltes de albayalde son planos y muy mecánicos -como acontece en las mangas, o en las predecibles arrugas del manto-, y carecen del carácter difuso que se evidencia, por ejemplo, en la antedicha Magdalena. Las anatomías son pobres e incorrectas, privadas del dulzor de los estilemas joa-

\footnotetext{
106 https://www.museodelprado.es/coleccion/obra-de-arte/la-magdalena-al-pie-de-la-cruz/3e478edd-c7cb-4e54-bba6-5c90f0fe 0754? searchid=408ab80b-6702-9411-6fa3-5179e82e7e8d

107 BENITO, Fernando, 2000 a, p. 62 y 182.

108 https://www.britishmuseum.org/research/collection_online/collection_object_details.aspx?objectld=717607\&partld=1\&images=true

109 BENITO, Fernando, 2000a, pp. 98-99.

110 McDONALD, Mark, 2012, p. 165 y 289, n. 14

111 AMES-LEWIS, Francis, 2000, pp. 63-90 y BOUBLI, Lizzie, 2003, pp. 35-60. Sobre los ejercicios de copia de este tipo de modelos véase BAMBACH, Carmen, 1999 y HERRERO-CORTELL, Miquel A, 2018 a.
} 

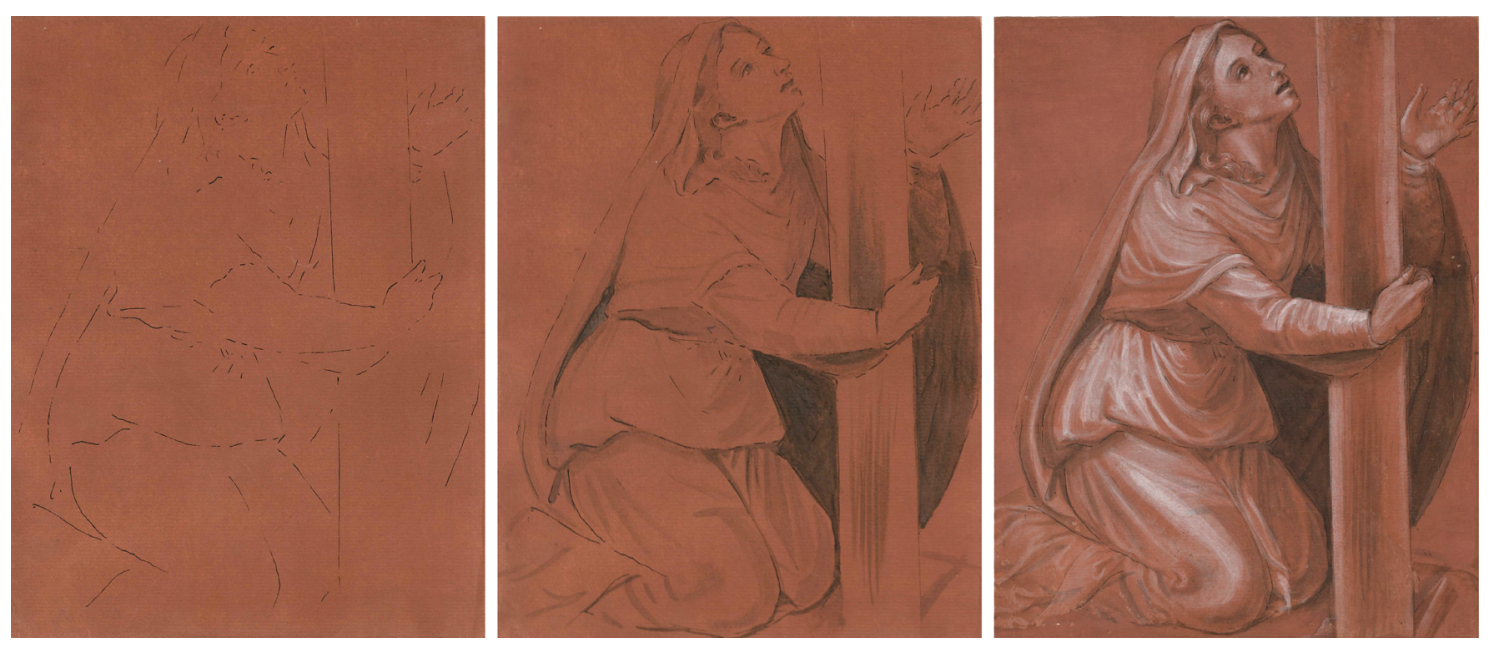

Fig. 6. Reconstrucción del proceso de creación de la Santa María Magdalena del Museo del Prado.

nescos: manos de dedos cortos y de escorzo equivocado; imperfecto rostro asimétrico de ojos casi estrábicos; y cabellos muy simplificados, ajenos del verismo del maestro. A todo ello se suma la escala: una simple comparativa con el resto de ejemplares pone de manifiesto que una figura de tal tamaño debería haberse resuelto con mucha mayor calidad y nivel de detalle, en confrontación con los estándares del valenciano. En definitiva, una obra que, en lo sucesivo, debería considerarse de un discípulo o seguidor que, a lo sumo, debe ubicarse en la órbita del taller, y que, probablemente, reproduzca un modelo ya acabado.

Por lo que respecta al San Jerónimo del Museo de Bellas Artes de Valencia (inv. 8.540), sigue un modo de hacer muy similar al de la virgen sedente. Un papel ligeramente teñido con aguadas monocromas y algunos resaltes de albayalde. Por la apariencia formal y los estilemas faciales más recuerda a Vicente Joanes que a su padre, pudiendo ser, probablemente, un papel de obrador, muy en relación, por ejemplo, con el Ángel con arma Christi.

Para concluir no podemos pasar por alto un dibujo que, con total seguridad no es de mano de Joanes, aunque casi con total certeza proviene efectivamente de su obrador, ${ }^{112}$ aunque había sido tradicionalmente tenido como autógrafo. ${ }^{113}$ Nos referimos al dibujo de San Vicente y los Santos Már- tires, que reproduce una de las escenas del Retablo de la Trinidad del Gremio de Pelaires de Valencia, conservado también en el Museo de Bellas Artes de dicha ciudad. Podría tratarse de una copia de taller, como ya observaba Benito, ${ }^{114}$ realizada como registro del modelo, pese a que había sido tradicionalmente tenido por obra de Joanes, pero los estilemas de las figuras, las manos y pies y unas fisonomías algo simplificadas y de gesto exagerado, lo alejan de la mano del maestro. Sin embargo, se trata de un dibujo muy detallado y con el mismo tipo de técnica, por ejemplo, que la Santa Cena de ese mismo museo, razones que lo acercan, a nuestro parecer, al ámbito de su obrador. El diseño incorpora los querubines de la Trinidad Coronando a la Virgen del cuerpo ático.

\section{Hacia una conclusión}

La obra gráfica de Joan de Joanes bien merecía una revisión en términos diversos a los que tradicionalmente se le han aplicado. De hecho, toda la producción artística del pintor merece algunas reflexiones que arrojen algo de luz sobre su modo de trabajar, sobre su formación, sobre su taller o sobre otros aspectos de su todavía oscura biografía; reflexiones que permitan poner de manifiesto la excepcionalidad de su talento artístico, -a menudo subestimado por motivos que no se explican si no hay detrás un cierto complejo de inferioridad-. Y es que,

112 McDONALD, Mark, 2012, p. 165 y 289, n. 14.

113 ANGULO, Diego; PÉREZ SÁNCHEZ, Alfonso E., 1975.

114 BENITO, Fernando, 2000 a, p. 94. 
Joanes no fue un mero pintor provinciano, ni una copia vacua de Macip. No fue un mero artesano iletrado, sino un artista culto y bien posicionado; un maestro del arte de la pintura conocedor del oficio a la manera italiana y a la flamenca. Lo sabía bien Lorenzo Hernández Guardiola. ${ }^{115}$

No ha sido hasta las últimas décadas que se ha comenzado un esbozo del retrato artístico de Joan de Joanes: primero con un par de tentativas de ordenación de su corpus pictórico, ${ }^{116}$ que acabaron por emancipar de una vez su personalidad, separándola de la de su padre; ${ }^{117}$ y más recientemente con la edición del compendio de documentos biográficos alusivos a la saga de los Macip. ${ }^{118}$ En los últimos años estamos proponiendo una serie de revisiones de las aportaciones joanescas con un enfoque técnico, procedimental e iconográfico. Pero son todavía muchas las preguntas sin respuesta que salpican el conocimiento de su producción. ¿Cuánto débito profesa el ductus gráfico de Joan de Joanes hacia el de su padre, Vicent Macip? ¿Qué peso tuvo la tradición local valenciana en la configuración de tal ductus? ¿Es la visualización de otras obras y grabados italianos la responsable de su marcado italianismo? ¿Qué funciones tienen los dibujos de Joanes en el contexto de su producción pictórica, más allá de la configuración de un repertorio de taller?

En un sentido técnico debe admitirse que Joan de Joanes fue prácticamente un adelantado en aspectos procedimentales: utilizaba los mismos registros gráficos que los artífices florentinos y romanos; los mismos que aprendían los artistas flamencos que, seducidos por lo italiano, ponían rumbo a aquel país en un periplo de aprendizaje. En este sentido, Joanes dominaba bien las técnicas del plumier: se desenvolvía con soltura con el lápiz negro y el carbón; hacía discurrir la pluma con tanta maestría como destreza, pasando de los borrones gestuales a la precisa miniatura; y sus aguadas eran tan delicadas que imbuían de precioso pictoricismo sus dibujos. Hacía gala de múltiples registros en función de la utilidad de sus diseños: desde el esquema conceptual o el boceto, hasta el estudio de las figuras o los ropajes; desde la fijación general de la composición hasta el registro de la misma, a veces a manos de sus discípulos. Precisamente los vestigios de su obrador -el más prolífico en suelo peninsular en su siglo- se rastrean en este elenco de evidencias gráficas: cuadrículas, estudios de drapeados y de luces, copias, muestras, folios del repertorio de taller, etc. Conviene considerar que tal suma de soluciones suponía toda una novedad en la España de su tiempo, y que los ecos que aquí llegaron de las técnicas italianas lo hicieron mayormente ya superado el ecuador de 1550. Así, no es de extrañar que diseños de Pellegrino Tibaldi o Romulo Cincinatto, casi medio siglo posteriores, sean tan parecidos a los de Joanes, -tan sorprendentemente acordes con la vanguardia artística de su tiempo-, como bien describe Francisco de Holanda en 1550.

El dibujo es, como la caligrafía, algo arraigado en el inconsciente del pintor. Cuesta de imitar, de forzar y se consolida en la infancia y en la adolescencia, acabándose de perfilar en los años de juventud. El dibujo de Joan de Joanes se aleja demasiado del de su padre y del de los pintores de su generación. Como ya se evidenciaba en el caso de los diseños subyacentes ${ }^{119}$ el ductus de Joanes no parecía depender del de su progenitor, sino que era algo nuevo. De este modo, en su obra gráfica se confirma esta discordancia, lo que sugiere que el grueso de su formación no debió transcurrir en el taller paterno. La cercanía de modelos y técnicas italianas difícilmente puede ahora explicarse solo a través de la visualización de unas pocas obras y algún cuaderno de grabados. La hipótesis de una etapa de formación italiana va tomando cada vez más fuerza.

Agotadas las vías documental y formal se precisa de otras aproximaciones metodológicas para seguir avanzando en el conocimiento de la obra del que probablemente sea uno de los pintores más influyentes del Renacimiento hispano. ${ }^{120}$ Sin duda un análisis de su técnica gráfica y pictórica puede ayudar a encontrar respuesta a tantas incógnitas. Para acabar de perfilar el retrato de una personalidad tan compleja y poliédrica como la de Joan de Joanes queda aún mucha tinta en el tintero.

\footnotetext{
115 HERNÁNDEZ GUARDIOLA, Lorenzo, 2009.

116 ALBI, José, 1979; así como BENITO, Fernando; GALDÓN, José Luis, 1997.

117 BENITO, Fernando, 2000 a.

118 PUIG, Isidro; COMPANY, Ximo; TOLOSA, Lluisa, 2015.

119 HERRERO-CORTELL, Miquel A.; PUIG, Isidro, 2018 b.

120 HERNÁNDEZ GUARDIOLA, Lorenzo, 2009.
} 


\section{Bibliografía}

ALBI, José. Joan de Joanes y su círculo artístico, 3 vols., Valencia, Institución Alfonso el Magnánimo, 1979.

AMES-LEWIS, Francis. Drawing in Early Renaissance Italy. London: Yale University Press, 2000 (1982).

ANGULO, Diego; PÉREZ SÁNCHEZ, Alfonso E. A corpus of Sapnish Drawings 1400-1600. London, 1975.

ANSÓN, Arturo; CENTELLAS, Ricardo (com.). Dibujo español del Renacimiento a Goya: la colección de la reina Maria Cristina de Borbón. (Palacio de Sástago, Diputación Provincial de Zaragoza, sala de exposiciones de Cajalón, 7 octubre - 8 diciembre de 2008). Zaragoza: Diputación Provincial, 2008.

ÁVILA, Ana. Imágenes y símbolos en la arquitectura pintada española (1470-1560). Barcelona: Anthropos, 1993.

BAMBACH, Carmen. Drawing and Painting in the Italian Renaissance Workshop. Theory and Practice, 13001600. Cambridge: Cambridge University Press, 1999.

BARRACHINA, Jose M. Sant Espirit. Real Monasterio de Santo Espíritu del Monte. Valencia: 2003.

BENITO, Fernando. "Fuentes icónicas empleadas por Vicente Macip y Joan de Joanes en sus cuadros del Prado y otras pinturas". Boletín del Museo del Prado, 1993, vol. 14, n. 32, pp. 11-24.

BENITO, Fernando. Ferrando Spagnuolo e altri maestri iberici nell'Italia di Leonardo e Michelangelo. (Firenze, Casa Buonarruoti, 1998. Valencia: Generalitat Valenciana, 1998.

BENITO, Fernado (com). Joan de Joanes. Una visión del artista y su obra. (Valencia, Museo de Bellas Artes de Valencia, 31 enero - 26 marzo de 2000). Valencia: Generalitat Valenciana, 2000 a.

BENITO, Fernando (com). Joan de Joanes un maestro del Renacimiento. (Valencia, Museo de Bellas Artes, 3 octubre - 26 de noviembre 2000). Valencia: Generalitat Valenciana, Fundación Santander Central Hispano, $2000 \mathrm{~b}$.

BENITO, Fernando; GALDÓN, José Luis. Vicente Macip (h. 1445-1550). (Valencia, Museo de Bellas Artes, 24 febrero - 20 abril, 1997). Valencia: Generalitat Valenciana, 1997.

BOMFORD, David, (ed.). Underdrawings in Renaissance Paintings: Art in the Making - Catalogue to National Gallery Exhibition, London London: GSK, 2002.

BOUBLI, Lizzie. L'atelier du dessin italien à la Renaissance. Variante et Variation. Paris: CNRS, ed., 2003.

BOUBLI, Lizzie. Le dessin en Espagne à la Renaissance. Pour une interprétation de la trace. Paris: Brepols, 2015.

CENNINI, Cennino. I/ libro del Arte. Edición digital completa en: https://www.ilpalio.siena.it/5/Personaggi/ CenninoCennini

COMPANY, Ximo; ALIAGA, Joan (com.), Lux Mundi La Luz de las Imágenes. Xàtiva, Generalitat Valenciana, Fundación La Luz de las Imágenes. 2007.

COMPANY, Ximo; ALIAGA, Joan (com.), San Francisco de Borja Grande de España. Arte y espiritualidad en la cultura hispánica de los siglos XVI y XVII, (Gandía, Casa de la Cultura Marqués de González de Quirós, del 4 de noviembre de 2010 al 9 de enero de 2011). Valencia, Ayuntamiento de Gandia, Universidad de Lleida, 2010.

COMPANY, Ximo; PUIG, Isidro, "Sagrada Familia con san Juanito. Joan de Joanes", En: Company, X.; Aliaga, J. (com.), San Francisco de Borja Grande de España. Arte y espiritualidad en la cultura hispánica de los siglos XVI y XVII, Valencia, 2010. 190-193, num. 9.

COMPANY, Ximo; VILALTA, M. José; PUIG, Isidro (eds.), El rol de lo hispánico en la configuración de la pintura mediterránea de los siglos XV y XVI. Lleida, 2009.
CONTRERAS, Gemma. "Componentes inorgánicos de las tintas metalogálicas: su nomenclatura en las fuentes originales y algunas notas sobre su comercio y extracción". MoleQla: revista de Ciencias de la Universidad Pablo de Olavide, 2014, n. 13, pp. 24-33.

CONTRERAS, Gemma. La tinta de escritura en los manuscritos de archivo valencianos, 1250-1600. Análisis, identificación de componentes y valoración de su estado de conservación. Tesis Doctoral. Universitat de València, 2015.

DACOS, Nicole. Viaggio a Roma. I pittori Europei nel' 500. Milán: 2012.

DE HOLANDA, Francisco. De la pintura antigua (1563). Madrid, Visor, 2003.

DI GIAMPAOLO, Mario (ed.). Disegni emiliani del Rinascimento. Modena: Casa di Risparmio di Modena / Amilcare Pizzi Eitore, 1989.

ESPINÓS, Adela. Museo de Bellas Artes de Valencia. Catálogo de dibujos. Valencia: Museo de Bellas Artes, 1979.

FAIETTI, Marzia; GALLORI, Corinna, MOZATTI, Tommaso (com.). Spagna e Italia in dialogo nell'Europa del Cinquecento. Firenze: Giunti, 2018.

FINALDI Gabriele; GARRIDO, Carmen (com.). El trazo oculto. Dibujos subyacentes en pinturas de los siglos XV y XVI. (Madrid, Museo del Prado, 21 de julio-5 de noviembre de 2006). Madrid, Ministerio de Cultura, 2006.

GARRIDO, Carmen. "Albert Dürer: deux manières différentes de travailler" En: VEROUSTRATAETE, H.; VAN SCHOUTE, R. (eds.). Le dessin sous-jacent dans la peinture. Le peinture dans le Pays-Bas au 16e siècle. Colloque XI (14-16 septiembre 1995) Lovaina-la Nueva, 1997, pp. 61-66, pl. 23-29.

GARRIDO, Carmen. "Aplicación de la metodología científica al estudio de la pintura". En: Arte: materiales y conservación. Fundación Argentaria, 1998, pp. 41-65.

GARRIDO, Carmen; BERTANI, Duilio (com.). El nacimiento de una pintura. De lo visible a lo invisible, (Museo de Bellas Artes de Valencia, 14 julio - 14 noviembre 2010). Valencia, Generalitat Valenciana, 2010.

GOLDNER, George; BABMACH, Carmen. The drawings of Filippino Lippi and his circle. New York: Abrams, 1997.

GÓMEZ ARRIBAS, Antonio. La Santísima Trinidad. Un dibujo de Joan de Joanes en el Monasterio de Santo Espíritu del Monte de Gilet. 2014.

GONZÁLEZ GARCÍA, Juan Luis. "Ut pictura rhetorica: Juan de Juanes y el retablo de San Esteban de Valencia. Boletín del Museo del Prado, 1999, vol. 17, n. 35, pp. 21-56

HERNÁNDEZ GUARDIOLA, Lorenzo. "Italia revivida en la obra de Juan de Juanes, el mejor pintor español del siglo XVI", En: COMPANY, X.; VILALTA, M.J; PUIG, I. (eds.). El rol de lo hispano en la pintura mediterránea de los siglos XV y XVI. Lleida, 2009, pp. 291-325.

HERRERO-CORTELL, Miquel A.; "Del sacar de otras pinturas. Consideración de las copias pictóricas a la luz de los tratados y otros textos del Renacimiento: reputación teórica versus repercusión práctica". Revista de Humanidades, n. 35, 2018 a, pp. 81-106.

HERRERO-CORTELL, Miquel A.; "De Re Pictorica. Libros, tratados y recetarios en la época de Joan de Joanes y su posible influencia en la obra del pintor valenciano". En: La formación artística: Creadores-Historiadores-Espectadores. Universidad de Cantabria, 2018 b, pp. 1329-1342.

HERRERO-CORTELL, Miquel A.; PUIG, Isidro. "Fernando de Llanos y la fortuna de la Virgo Lactans. Consideraciones técnicas y estilísticas para el estudio de un modelo de Virgen de la Leche en el Renacimiento valenciano". Archivo de Arte Valenciano, n. 98, 2017, pp. 53-78. 
HERRERO-CORTELL, Miquel A.; PUIG, Isidro. "Evidencias de procesos mecánicos y semimecánicos de copia en pinturas de la Edad Moderna: algunos casos prácticos". RHA, Revista de História da Arte, n. 7, 2018 a, pp. 8-18.

HERRERO-CORTELL, Miquel A.; PUIG, Isidro. "El trazo velado delata al maestro. Dibujos subyacentes en la obra pictórica de Joan de Joanes: de la creación a las prácticas de taller". Archivo de Arte Valenciano, n. 99, 2018 b, pp. 35-57.

MARTíNEZ, Jusepe. Discursos practicables del nobilísimo arte de la pintura [1672]. Manrique, E. (ed.), Zaragoza, 2008 (también consultada ed. de 1988).

McDONALD, Mark. Renaissance to Goya: prints and drawings from Spain. London: British Museum Press, 2012.

McDONALD, Mark. "Il disegno in sapgna. 1500-1600". En: FAIETTI, Marzia; GALLORI, Corinna, MOZATTI, Tommaso (com.). Spagna e Italia in dialogo nell'Europa del Cinquecento. Firenze: Giunti, 2018, pp. 38-57.

MONTERO, Encarna. "El cuaderno de dibujos de los Uffizi: Un ejemplo, tal vez, de la transmisión del conocimiento artístico en Valencia en torno a 1400". Ars Longa, $\mathrm{n}^{\circ} 22$, 2013, pp. 55-76.

MONTERO, Encarna. La transmisión del conocimiento en los oficios artísticos: Valencia, 1370-1450. Valencia: Institució Alfons el Magnànim, 2015.

MULLER, Priscilla E. "Juan de Juanes: un dibujo problemático". Archivo Español de Arte, 1976, vol. 49, no 194, pp. 176-179.

NAVARRETE, Benito (dir.). I segni del tempo. Dibujos españoles de los Uffizi. Madrid: Fundación -MAPFRE, Galleria degli Uffizi, 2016.

NAVARRETE, Benito. "I disegni spagnoli del XVI secolo: problemi di definizione, attribuzione e identità". En: FAIETTI, Marzia; GALLORI, Corinna, MOZATTI, Tommaso (com.). Spagna e Italia in dialogo nell'Europa del Cinquecento. Firenze: Giunti, 2018, pp. 52-79.

POLDI, G.; VILLA G. C. Dalla conservazione alla storia dell'arte. Riflettografia e analisi non invasive per lo studio dei dipinti. Pisa: Edizioni della Normale, 2006.

PUIG, Isidro. "La fotografía digital infrarroja en los aná- lisis estilísticos de la pintura de los siglos XV y XVI". En: Il Jornades d'Art: Pintura dels segles XV i XVI a la Corona d'Aragó, Xàtiva, 2010, pp. 87-102.

PUIG, Isidro: "Una obra de Joan de Joanes, localizada y revisada iconográficamente". Ars longa: cuadernos de arte, núm. 22, 2013 a, pp. 111-117.

PUIG, Isidro. "Sobre dos pinturas de Juan de Juanes en las colecciones Lladró y Laia-Bosch". Boletín del Seminario de Estudios de Arte y Arqueologia, LXXIX, 2013 b, pp. 69-82.

PUIG, Isidro; COMPANY, Ximo; TOLOSA, Lluisa. El pintor Joan de Joanes y su entorno familiar. Los Macip a través de las fuentes literarias y la documentación de archivo. Lleida, Universitat de Lleida, 2015.

PUIG, Isidro; HERRERO-CORTELL, Miquel A. "Nuevas aportaciones al corpus pictórico valenciano del primer renacimiento: Rodrigo de Osona, Maestro de Perea y Pere Cabanes I". Archivo de Arte Valenciano, 2016, vol. 97, pp. 53-65.

PUIG, Isidro; HERRERO-CORTELL, Miquel A. "Un San jerónimo de Joan de Joanes". En: Company, X; Rega, l; Puig, I. (eds.). Miradas a la pintura de Época Moderna entre España e Italia. Lleida, 2017. https://doi.org/ 10.21001/mpemei.2017

RAGGHIANTI, Carlo L. et alt. Mostra d'arte Fiamminga e Olandese dei secoli XV e XVI. (Fienze, Palazzo Strozzi, maggio-ottobre 1947). Firenze: Sansoni, 1948.

SMITH, Stan. Dibujar y abocetar. Madrid: Ediciones AKAL, 1994.

THOMAS, Anabel. The painter's practice in Renaissance Tuscany. Cambridge, UK: Cambridge University Press, 1995.

VAN ASPEREN DE BOER, Jan. "The study of underdrawing. An assessment". En: Van Schoute, R. (ed.). Le dessin sous-jacent dans la peinture. Colloque $V$. (Louvain-la-Neuve, 29-30 septembre - 1 er octubre 1983). Lovaina: Université Catholique de Louvain, 1985, pp. 12-17.

VASARI, Giorgio. Las vidas de los más excelentes arquitectos, pintores y escultores italianos desde Cimabue hasta nuestros días. Madrid: Cátedra, 2002. 